\title{
Fatigue Evaluation of Steel Bridge Details Integrating Multi-Scale Dynamic Analysis of Coupled Train-Track-Bridge System and Fracture Mechanics
}

\author{
Huile Li * and Gang Wu \\ Key Laboratory of Concrete and Prestressed Concrete Structures of the Ministry of Education, National and \\ Local Joint Engineering Research Center for Intelligent Construction and Maintenance, Southeast University, \\ Nanjing 211189, China; g.wu@seu.edu.cn \\ * Correspondence: huile.li@seu.edu.cn
}

Received: 29 March 2020; Accepted: 4 May 2020; Published: 7 May 2020

check for updates

Featured Application: The presented framework has a potential application of enhanced fatigue assessment of steel railway bridges with respect to fatigue-prone structural details.

\begin{abstract}
Increased running speed and axle weight in the transportation network lead to significant dynamic interactions between the vehicles and bridges. It is essential to capture these interactions in fatigue analysis of steel bridges. This paper presents a framework for fatigue evaluation of critical steel bridge details through multi-scale dynamic analysis of the train-track-bridge system and linear elastic fracture mechanics. The multi-scale coupled dynamic analysis allows accurate and efficient computation of fatigue stresses produced by the moving trains in structural details based on a vehicle-bridge analysis model composed of a $3 \mathrm{D}$ vehicle model, multi-scale bridge finite element model including the track system, and a wheel-rail interaction model. Field data from an existing steel-truss railway bridge are used to validate the multi-scale analysis method. Enhanced fatigue evaluation of the bridge detail is performed using the computed fatigue load effects and linear elastic fracture mechanics. The effects of the track irregularity and operating train speed on fatigue crack propagation life are investigated. The presented framework is general and can be applied to other types of steel bridges such as the steel-box girder bridge with orthotropic decks.
\end{abstract}

Keywords: fatigue evaluation; steel bridge; train-track-bridge system; multi-scale dynamic analysis; linear elastic fracture mechanics; fatigue crack propagation

\section{Introduction}

With the development of economy and society, traffic networks have evolved toward high operating speeds and heavier transportation weight. Bridges serving as key nodes of the transportation infrastructure network are accordingly subjected to vehicles with higher moving speeds and larger axle loads in comparison with that in the past [1,2]. As a result, the dynamic interactions between vehicles and bridge structures have become more and more significant. These growing interactions may cause critical threats to the fatigue life of steel bridges by producing excessive stress ranges and applied cycle counts.

In order to determine the fatigue load effects, the computation of dynamic stresses due to vehicle loadings is a fundamental step in fatigue evaluation of steel bridges. Both the predicted fatigue damage and fatigue life can be sensitive to the obtained stress results. In the fatigue analysis of steel railway bridges, the static method has been adopted to calculate the fatigue stresses. Railway vehicles can be treated as a set of vertical concentrated forces applied on the numerical bridge model. Subsequently, static structural analysis is performed by considering the impact effects of moving vehicles with a dynamic amplification factor [3,4]. It was reported in Liu et al. [5] that a safe 
dynamic amplification factor might not guarantee a safe evaluation of the bridge fatigue damage. Another method for fatigue stress computation is the moving load analysis. In this method, dynamic analysis was conducted to obtain the fatigue stresses by modeling the vehicles as vertical moving forces [6-9]. Both the abovementioned methods have proven to be efficient in multiple cases such as preliminary fatigue analysis of the bridges to identify fatigue-prone members. Since the vehicle-bridge dynamic interactions are not accurately captured by the static and moving load methods, more systematic methods may be required for the stress calculation in fatigue assessment.

An attempt to considerthe dynamic interactions between the train and bridge in fatigue life estimation of a steel-truss riveted railway bridge has been made by using a simplified partial bridge model and the three degrees-of-freedom (DOFs) vehicle model [10]. For fatigue assessment of highway bridges, coupled vehicle-bridge system models were developed to compute the fatigue stresses in several studies [11-14]. Two important aspects of the coupled vehicle-bridge system, i.e., vehicle speed and road roughness, can significantly affect the bridge fatigue reliability [12]. A three DOFs vehicle model in the vertical plane coupled with the bridge model was built by Liu et al. [5] to investigate the fatigue behavior of a composite high-speed railway bridge. Recently, a coupled train-bridge system model composed of a 3D vehicle model, a 3D bridge finite element $(\mathrm{FE})$ model established with the direct stiffness method, and the wheel-rail interaction model were developed by Li et al. [15-17] to compute bridge dynamic stresses and to further perform deterministic and probabilistic fatigue evaluation. In those studies, significant differences in both the calculated fatigue stress and damage resulting from the static method, the moving load method, and coupled train-bridge dynamic analysis were found for structural members of the bridge deck system (e.g., stringer and floor beam). Furthermore, in spite of the consideration of train-bridge dynamic interactions, fatigue assessment was carried out at the structural member level (i.e., stringer) based on the calculated nominal stresses and the S-N approach. Due to complex geometric configurations and stress conditions, the structural details might not belong to any of the fatigue categories prescribed in the associated codes and therefore cannot be handled with the nominal stress based S-N approach [18]. These structural details, however, may be more critical compared with the major structural members from the fatigue point of view. Overall, very few studies can be found focusing on the fatigue evaluation of fatigue-prone details in the steel railway bridges with the coupled dynamic effects of the train-track-bridge (TTB) system included.

The contribution of this paper lies in proposing a framework for fatigue evaluation of steel bridge details based on multi-scale dynamic analysis of the coupled TTB system and linear elastic fracture mechanics (LEFM). In this framework, multi-scale vibration analysis of the TTB system leads to accurate and efficient fatigue stress computation of structural details and the integration of LEFM allows enhanced fatigue analysis with insights into the fatigue crack propagation of critical details. Specifically, a multi-scale bridge FE model including the model of the track system is established and incorporated into a vehicle-bridge interaction model to achieve coupled dynamic analysis of the TTB system. Accurate stress calculation of both the primary structural members and fatigue-critical structural details considering the TTB interactions is realized simultaneously with reasonable computation costs. Stress responses of a real steel-truss railway bridge obtained from the multi-scale coupled dynamic analysis are compared with the field data measured in a bridge inspection. Fatigue crack propagation history of the stringer-to-floor-beam connection bracket in the bridge deck system is subsequently predicted using the theory of LEFM. The influential factor of fatigue crack initiation and propagation is discussed. Additionally, effects of track irregularity and operating train speed on the fatigue crack propagation life of the critical detail under consideration are investigated.

\section{Multi-Scale Bridge FE Model}

In this section, the multi-scale FE model of a steel-truss railway bridge, i.e., the Baihe Bridge, is established and elaborated to conduct fatigue crack propagation analysis of critical structural details. In addition, this multi-scale bridge FE model represents an important part of the coupled TTB system analysis introduced in the following section. 


\subsection{Engineering Background}

The Baihe Bridge, opened to traffic in 1980, lies on the Beijing-Tongliao Railway Line connecting Beijing and the Inner Mongolia Autonomous Region (Figure 1). The railway line is one of the major links between Beijing, the capital city, and Northeast China. With a total length of $804 \mathrm{~km}$, it carries both passenger and cargo transportation. The Baihe Bridge, one of the key bridge projects in this railway line, spans the Miyun Reservoir in the northeast of Beijing. As shown in Figure 2, the bridge is a three-span continuous steel-truss structure, and each span has an identical length of $128 \mathrm{~m}$. Two main trusses consisting of upper chords, lower chords, posts, and diagonals are separated by $8.0 \mathrm{~m}$. The height of each truss is $13.4 \mathrm{~m}$ and the distance between two adjacent truss joints is $8.0 \mathrm{~m}$.

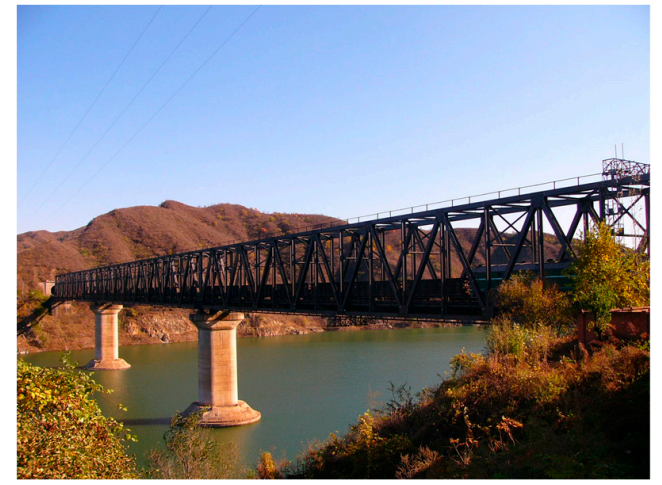

(a)

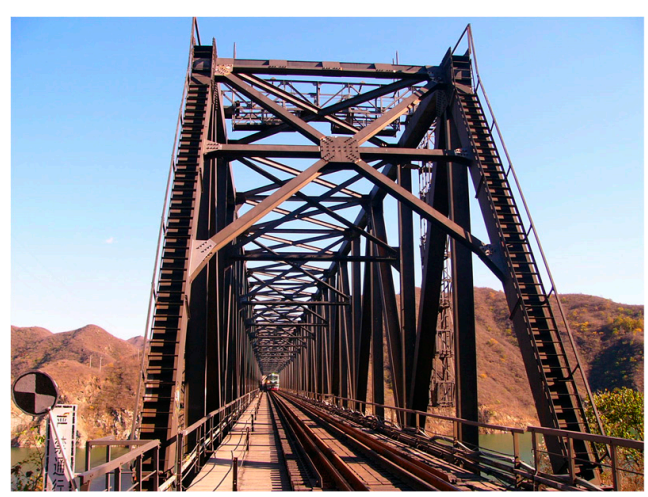

(b)

Figure 1. Photograph of the Baihe Bridge: (a) global view; and (b) open deck system.

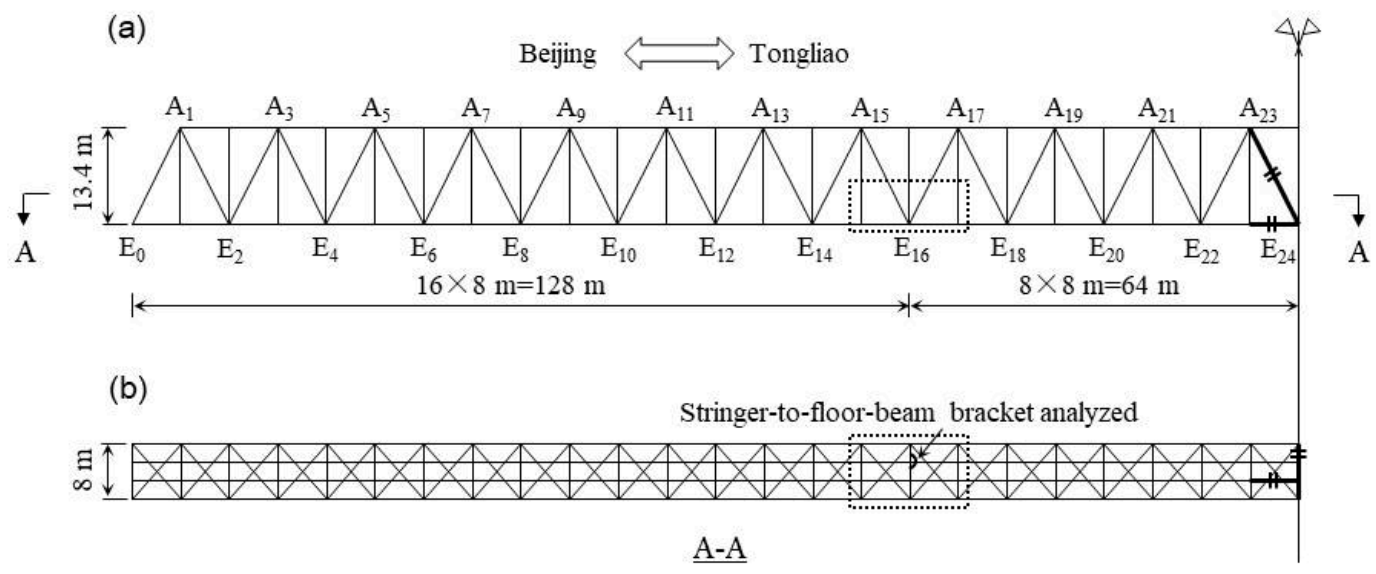

:..... Region where the local model is located II Measured cross-section of truss member in dynamic load test

(c)
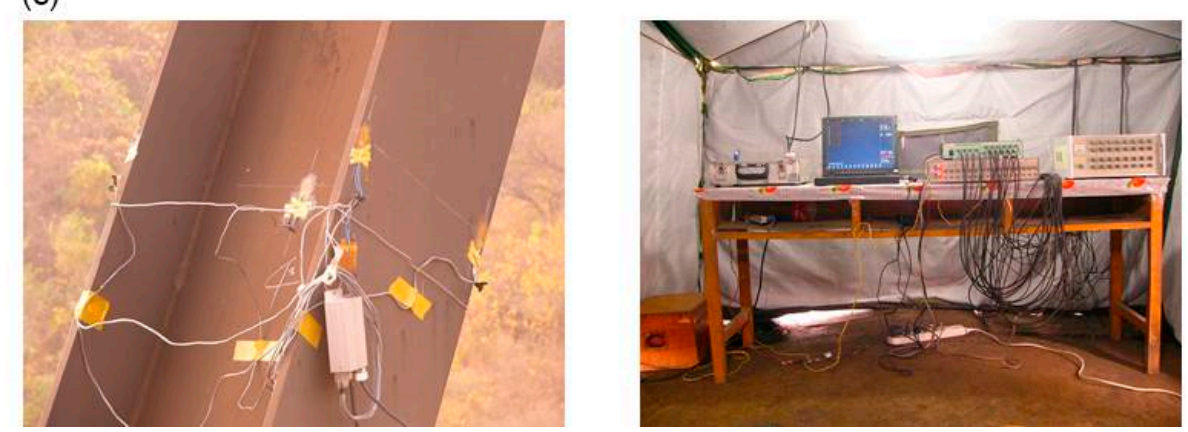

Figure 2. The Baihe Bridge: (a) elevation view; (b) top view of the stringer and floor beam system; and (c) strain gauges and data acquisition devices used in the field test. 
A single-track line is composed of the stringer and floor beam system of the bridge. Specifically, an open deck without ballast is adopted as shown in Figure 1, and therefore, two steel rails are directly supported by wooden sleepers that are connected with the two I-shaped stringers using hook bolts. In addition, I-shaped floor beams with the identical interval of $8 \mathrm{~m}$ can be considered as a series of elastic supports for the two stringers. The substructure of the Baihe Bridge is round-ended reinforced concrete piers built on a circular sunk shaft foundation. Hence, the substructure can be regarded as part of the earth due to its sufficient rigidity and it will not be included in the bridge FE model as established later on.

\subsection{Multi-Scale FE Modeling of the Baihe Bridge}

A global FE model of the Baihe Bridge was established by Li et al. [15]. Nevertheless, this model was purely composed of beam elements, aiming at dynamic stress analysis and fatigue damage evaluation at the primary truss member level. Although all of the section data of the beam elements were determined based on the cross-section dimensions of members in the design drawing, structural details such as the gusset plates of the main truss and component-to-component connections were ignored after considering both the analysis needs and computation costs. As a result, the beam element model cannot meet the requirements of enhanced fatigue evaluation associated with the abovementioned structural details. A refined FE model employing shell elements or solid elements for the entire bridge, however, could be inefficient due to huge computation efforts, especially in dynamic time-history analyses, which generally require small time steps.

In the preliminary fatigue analysis, the stringers around joint $\mathrm{E}_{16}$ (Figure 2) were identified as the fatigue-prone members [16]. The end configurations of stringers include the stringer-to-floor-beam bracket and connection angle with high-strength bolts as shown in Figure 3. The fatigue detail associated with the high-strength bolt connection angle was examined using the nominal stress-based S-N approach in [16]. However, fatigue cracks were discovered in the brackets at the position of joint $\mathrm{E}_{16}$ through the bridge routine inspection [19]. In consideration of the abovementioned information, the bracket is more critical from the fatigue point of view and a detailed local model shown in Figure 4 was developed within a longitudinal distance of about $22 \mathrm{~m}$ between the truss joint $E_{14}$ and joint $E_{18}$ using the ANSYS software [20]. In this local model, truss members, stringers, floor beams, longitudinal bracings, gusset plates, component-to-component connections and so on are simulated using the Shell181 elements with a fine mesh and as-built geometric configurations. Specially, smaller meshing sizes (about $20 \mathrm{~mm}$ ) are adopted in the vicinity of the critical stringer-to-floor-beam connection brackets compared with other areas (about $150 \mathrm{~mm}$ ) as shown in Figure 4. The size of $20 \mathrm{~mm}$ is determined on the basis that the stress results remain stable when the meshing size of the bracket is smaller than $30 \mathrm{~mm}$. In addition, considering the sufficient rigidity of the high-strength bolt connection among the bracket vertical plate, stringer bottom flange, and floor beam web, identical nodes are used at the interfaces of the bracket, stringer, and floor beam.

The local model consists of 24,897 shell elements and 26,594 nodes. The remaining parts of the Baihe Bridge are treated with Beam188 elements. The wooden sleepers and steel rails on the open deck are properly modeled in the present study (Figure 4), whereas only the mass of these two components were taken into account in $\mathrm{Li}$ et al. [15] by uniformly distributing it to the stringer and floor beam.

Appropriate connections between the local shell model and the beam model are needed to produce a reliable multi-scale bridge FE model. In this study, all the translation and rotation DOFs of the nodes in shell elements are coupled with the associated DOFs of the end nodes in beam elements at the interface of the shell and beam models (Figure 4). As a result, displacement compatibility and stress equilibrium can be expected to be achieved near the interface. In order to reduce the impact on stress computation accuracies due to the transition from beam elements to shell elements, the following aspects have been considered: (a) set sufficient distances in both longitudinal and vertical directions between the interface and the stringer-to-floor-beam connection bracket under investigation; and (b) 
avoid placing the interface in the locations that are subjected to intense and complex stress conditions such as the main truss joints.

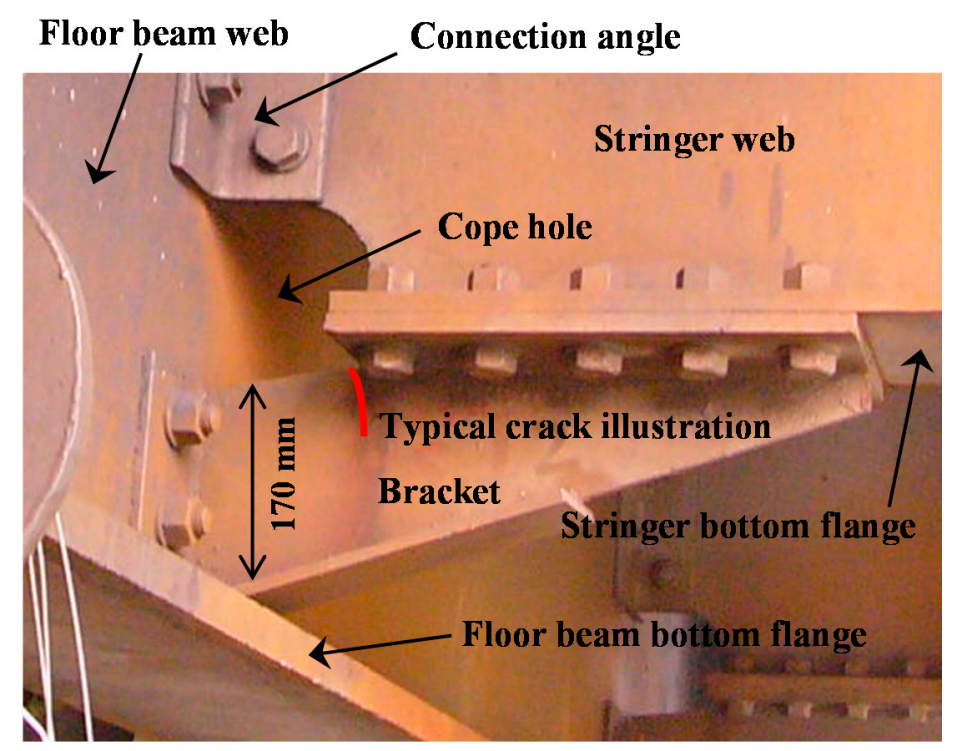

Figure 3. The stringer-to-floor-beam connection bracket.

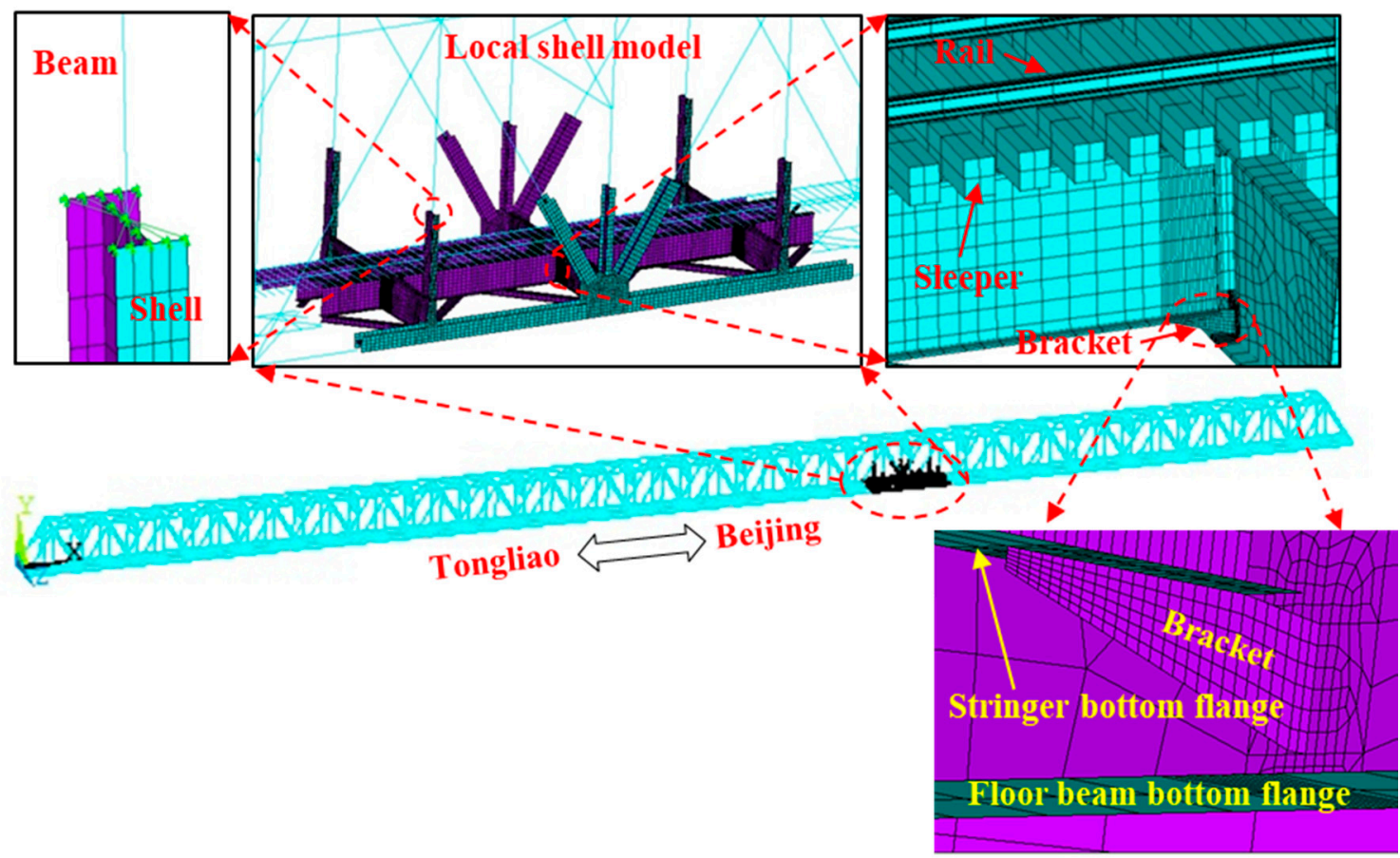

Figure 4. Multi-scale finite element (FE) model of the Baihe Bridge.

The material constants of the components of the Baihe Bridge were obtained based on the design documents as reported in Table 1. In particular, some truss chords, gusset plates, and connections including the stringer-to-floor-beam bracket were made of $15 \mathrm{MnVNq}$ steel with $420 \mathrm{MPa}$ yield strength. Other primary members of the bridge were produced using 16Mnq structural steel with $345 \mathrm{MPa}$ yield strength. Additionally, according to the design documents the fixed bearing is located at the end of the bridge near Beijing. 
Table 1. Material constants of the components in the Baihe Birdge.

\begin{tabular}{ccccc}
\hline Components & $\begin{array}{c}\text { Elastic Modulus } \\
(\mathbf{G P a})\end{array}$ & $\begin{array}{c}\text { Density } \\
\mathbf{( k g / \mathbf { m } ^ { 3 }}\end{array}$ & $\begin{array}{c}\text { Poisson's } \\
\text { Ratio }\end{array}$ & $\begin{array}{c}\text { Yield Strength } \\
(\mathbf{M P a})\end{array}$ \\
\hline Truss member, stringer, floor beam, and bracing & 206 & 7850 & 0.30 & 345 \\
Some truss chords, gusset, and connection & 206 & 7850 & 0.30 & 420 \\
Steel rail & 206 & 7850 & 0.30 & 630 \\
Wooden sleeper & 9 & 600 & 0.43 & N/A \\
\hline
\end{tabular}

Modal analysis of the multi-scale FE model of the Baihe Bridge shown in Figure 4 was performed with the ANSYS software. The first mode of vibration is transverse and the associated natural frequency is $1.05 \mathrm{~Hz}$. The first vertical and torsional modes of vibration were found to appear as the fourth and eighth modes of the bridge respectively, corresponding to the natural frequencies of $1.55 \mathrm{~Hz}$ and $2.65 \mathrm{~Hz}$. All three fundamental modes of vibration are shown in Figure 5. These results agree well with the counterparts from the beam model established in Li et al. [15]. Specifically, natural frequencies of the fundamental transverse, vertical, and torsional modes are $1.03 \mathrm{~Hz}, 1.55 \mathrm{~Hz}$, and $2.58 \mathrm{~Hz}$ based on the beam model. In addition, the fundamental transverse and vertical modal parameters were identified through the field testing as $1.04 \mathrm{~Hz}$ and $1.55 \mathrm{~Hz}$ [19]. Satisfactory comparison is achieved between the modal results of the multi-scale FE model and field testing.

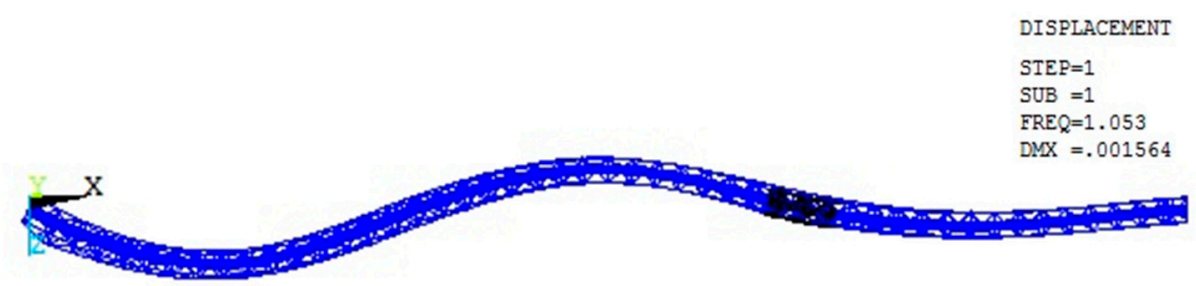

(a)

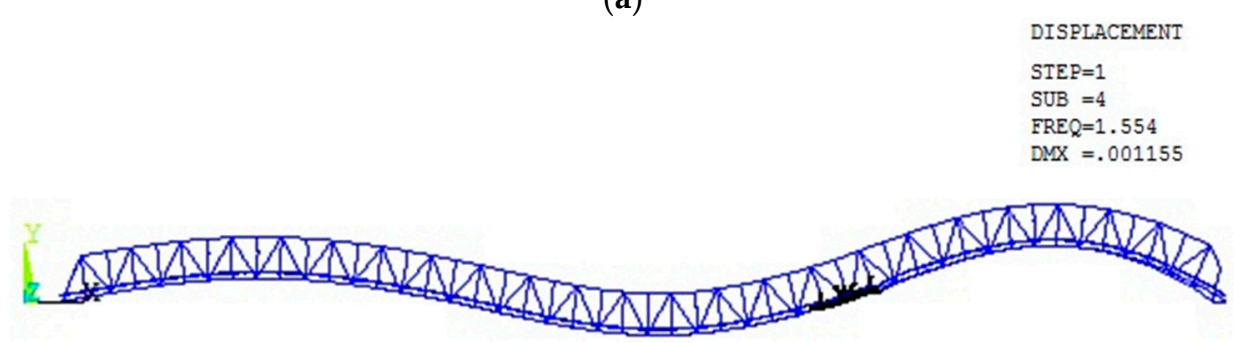

(b)

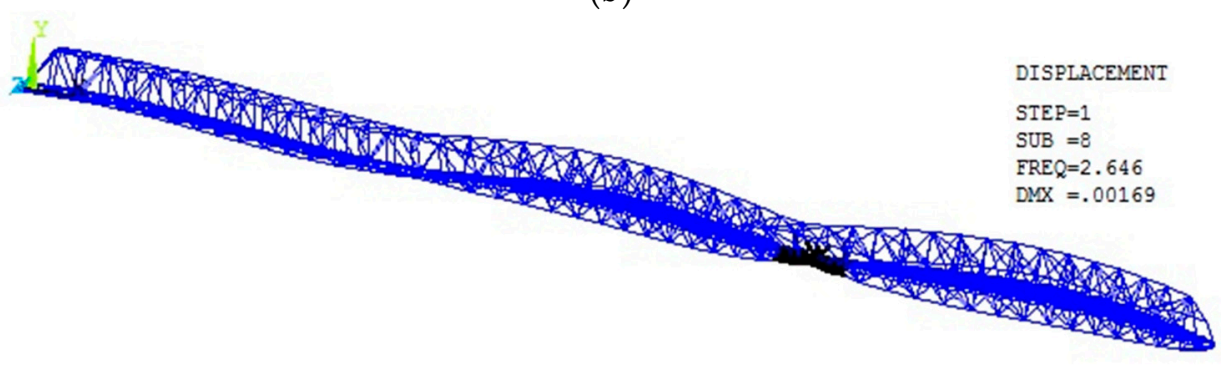

(c)

Figure 5. Fundamental mode shapes of the multi-scale FE model of the Baihe Bridge: (a) transverse; (b) vertical; and (c) torsional.

\section{Multi-Scale Coupled Vibration Analysis of the TTB System}

In this section, dynamic stress responses of the structural members and details in the Baihe Bridge are computed simultaneously by establishing a 3D vehicle-bridge interaction model for multi-scale vibration analysis of the TTB system. This interaction model consists of the vehicle subsystem and bridge 
subsystem including effects of the steel track that will be introduced separately. Subsequently, stress results obtained from the multi-scale dynamic analysis are compared with field measurements from the bridge routine inspection.

\subsection{TTB System Analysis Model}

Trains running over a bridge are actually time-variant dynamic loads [21,22]. Vibrations of the vehicle, track, and bridge are usually coupled and dynamic interactions exist among them [23-25]. Generally, the TTB system consists of the train subsystem, track subsystem, and bridge subsystem.

The train subsystem is modeled as a multiple-degree-of-freedom system composed of car-body, bogie, and wheelset, which can be regarded as rigid bodies. Without considering elastic deformations, both the car-body and bogie have five DOFs associated with rigid body movements, namely, swaying, rolling, yawing, floating, and pitching. Furthermore, the four DOFs of each wheelset are swaying, rolling, yawing, and pitching. The wheelsets are connected with the bogies through the primary suspension, while the bogies are connected to the car-body via the secondary suspension. Both the primary and secondary suspensions are modeled as the springs and dashpots of which the stiffness and damping parameters can be obtained from train manufacturers. Then, the equation of motion of the train subsystem can be established by using the Lagrange's equation $[15,26]$.

The equation of motion of the track subsystem can be expressed as fourth-order partial differential equations [27]. An integral model in which the track is included in the bridge subsystem was presented in Guo et al. [28]. In their study both the track and bridge structure were simulated by finite elements. The equation of motion of the bridge including the track was then formulated through the FE method. Since the present analysis is focused on dynamic stress responses of the bridge structure, the track model is incorporated into the bridge subsystem. Using the multi-scale FE model as discussed in the previous section, the equation of motion of the bridge subsystem can be established.

The dynamic interactions between the vehicle and bridge subsystems are associated with the motion of the vehicle and bridge, and track irregularities. In the present study, the linear wheel-rail interaction model proposed by Zhang et al. [29] is used to determine these interactions. Then, the equation of motion of the TTB system can be formulated by grouping the equations of motion of the train subsystem and bridge subsystem as:

$$
\left\{\begin{array}{l}
\mathbf{M}_{\mathrm{v}} \ddot{\mathbf{X}}_{\mathrm{v}}+\mathbf{C}_{\mathrm{v}} \dot{\mathbf{X}}_{\mathrm{v}}+\mathbf{K}_{\mathrm{v}} \mathbf{X}_{\mathrm{v}}=\mathbf{F}_{\mathrm{V}} \\
\mathbf{M}_{\mathrm{b}} \ddot{\mathbf{X}}_{\mathrm{b}}+\mathbf{C}_{\mathrm{b}} \dot{\mathbf{X}}_{\mathrm{b}}+\mathbf{K}_{\mathrm{b}} \mathbf{X}_{\mathrm{b}}=\mathbf{F}_{\mathrm{b}}
\end{array}\right.
$$

where $\mathbf{M}, \mathbf{C}$, and $\mathbf{K}$ are the mass, damping, and stiffness matrices; $\mathbf{X}, \dot{\mathbf{X}}$, and $\ddot{\mathbf{X}}$ are the time-variant displacement, velocity, and acceleration vectors respectively; subscripts $\mathrm{v}$ and $\mathrm{b}$ denote vehicle and bridge; and $\mathbf{F}_{\mathrm{v}}$ and $\mathbf{F}_{\mathrm{b}}$ are the vectors of dynamic interactive forces acting on the vehicle and bridge subsystems, respectively. Rayleigh damping is used for the bridge in the present analysis. Consequently, the damping matrix $\mathbf{C}_{b}$ can be expressed as the linear combination of mass matrix $\mathbf{M}_{b}$ and stiffness matrix $\mathbf{K}_{\mathrm{b}}$.

Equation (1) is subsequently solved by a numerical integration scheme, i.e., the Newmark- $\beta$ method, in order to acquire nodal displacements $\mathbf{X}_{\mathrm{b}}$ of the bridge FE model. With the knowledge of $\mathbf{X}_{\mathrm{b}}$, dynamic stresses of both the primary members and structural details can be computed simultaneously using the following formula as:

$$
\mathbf{S}_{\mathrm{b}}=\mathbf{E B X}_{\mathrm{b}}
$$

where $\mathbf{S}_{\mathrm{b}}$ is the vector of element stresses; $\mathbf{E}$ is the elastic matrix determined by element material properties; and $\mathbf{B}$ is the displacement-strain relationship matrix evaluated through derivative operations of the element shape function.

In this study, the multi-scale vibration analysis of the TTB system (i.e., solving Equations (1) and (2)) is performed by combining the MATLAB [30] procedure and ANSYS procedure. Firstly, the equation 
of motion of the train subsystem is solved using the program developed in MATLAB. It is assumed that the initial motion of the bridge is null. Accordingly, the excitations to the train subsystem are track irregularities of which the numerical samples are generated. Secondly, the wheel-rail interaction forces obtained from the previous iterative loop (or the first step) are applied to the multi-scale bridge FE model to compute updated time-histories of the bridge movement with the transient analysis module in ANSYS. Thirdly, using the updated bridge movement data and track irregularity samples as the excitations, the vehicle equation is solved and updated wheel-rail interaction forces are yielded. Finally, time-histories of wheel-rail interaction forces obtained in the third step and the previous iterative loop (or the first step) are compared to calculate the differences. If the differences are small enough, the computation can be considered as completed. Otherwise, the solution process continues from the second step until a satisfactory convergence is achieved. Specifically, convergence is checked in the present analysis by using the following formula as:

$$
\left|F_{\mathrm{v}}^{l}(t)-F_{\mathrm{v}}^{l-1}(t)\right| \leq \mathrm{Tol}
$$

where $F_{\mathrm{v}}^{l}(t)$ and $F_{\mathrm{v}}^{l-1}(t)$ are the vertical, lateral, or torsional wheel-rail interactions of each wheelset associated with time $t$ obtained by solving the vehicle equation of motion for the $l$ th iterative loop and (l-1)th iterative loop, respectively; and Tol represents the allowable tolerance. In this study, the values of Tol are set as $100 \mathrm{~N}, 10 \mathrm{~N}, 10 \mathrm{~N} \mathrm{~m}$ for the vertical, lateral, and torsional wheel-rail interaction forces, respectively. With the abovementioned scheme, stress responses of the bridge can be obtained in the post-processing module of the ANSYS software.

\subsection{Field Test Validation}

A dynamic load field test was performed on the Baihe Bridge in 2011 [19] (Figure 2). Detailed information about the field measuring campaign including the test train and measuring point layout can be found in $\mathrm{Li}$ et al. [17]. Stress time-histories of the several truss members (i.e., lower chord, post, stringer, and floor beam) marked in Figure 2 located in the center of the middle span obtained from the field test are compared with the results produced by multi-scale coupled vibration analysis of the TTB system.

Track irregularities adopted in the analysis are generated using the power spectral density functions $H$ ( ) fitted by the U.S. Federal Railroad Administration as:

$$
\left\{\begin{array}{l}
H_{\mathrm{a}}(\Omega)=\frac{0.25 \cdot A_{\mathrm{a}} \cdot \Omega_{\mathrm{c}}^{2}}{\Omega^{2} \cdot\left(\Omega^{2}+\Omega_{\mathrm{c}}^{2}\right)} \\
H_{\mathrm{v}}(\Omega)=\frac{0.25 \cdot A_{\mathrm{v}} \cdot \Omega_{\mathrm{c}}^{2}}{\Omega^{2} \cdot\left(\Omega^{2}+\Omega_{\mathrm{c}}^{2}\right)} \\
H_{\mathrm{c}}(\Omega)=\frac{A_{\mathrm{v}} \cdot \Omega_{\mathrm{c}}^{2}}{\left(\Omega^{2}+\Omega_{\mathrm{c}}^{2}\right) \cdot\left(\Omega^{2}+\Omega_{\mathrm{s}}^{2}\right)}
\end{array}\right.
$$

where $\Omega(\mathrm{rad} / \mathrm{m})$ is the spatial angular frequency; $H_{\mathrm{a}}, H_{\mathrm{v}}$, and $H_{\mathrm{c}}$ are, respectively, the lateral, vertical, and torsional irregularities in $\mathrm{cm}^{2} /(\mathrm{rad} / \mathrm{m}) ; \Omega_{\mathrm{c}}(\mathrm{rad} / \mathrm{m})$ and $\Omega_{\mathrm{s}}(\mathrm{rad} / \mathrm{m})$ are the cut-off frequencies; and $A_{\mathrm{a}}\left(\mathrm{cm}^{2} \mathrm{rad} / \mathrm{m}\right)$ and $A_{\mathrm{v}}\left(\mathrm{cm}^{2} \mathrm{rad} / \mathrm{m}\right)$ are the surface roughness constants.

The Federal Railroad Administration proposed that track irregularities can be categorized into six classes (i.e., class 1 to class 6) based on the measured data from various lines [31]. The four parameters $A_{\mathrm{a}}, A_{\mathrm{V}}, \Omega_{\mathrm{c}}$, and $\Omega_{\mathrm{s}}$ in Equation (4) for calculating the power spectral density and the allowed travel speed are reported in Table 2. It can be seen that tracks of class 6 have the highest allowed speed, and accordingly, the best track smoothness. Samples of the track irregularities are subsequently numerically produced through trigonometric series summation. In this study, power spectral densities associated with class 5 are adopted to simulate track irregularities on the Baihe Bridge since class 5 can characterize well the level of irregularity related to the regular main railway lines in China, e.g., the Beijing-Tongliao line [32]. 
Table 2. Power spectral density parameters and allowed train speed proposed by the U.S. Federal Railroad Administration.

\begin{tabular}{|c|c|c|c|c|c|c|}
\hline \multirow[b]{2}{*}{ Track Class } & \multicolumn{4}{|c|}{ Parameter } & \multicolumn{2}{|c|}{ Allowed Speed (km/h) } \\
\hline & $\begin{array}{c}A_{\mathrm{a}} \\
\left(\mathrm{cm}^{2} \mathrm{rad} / \mathrm{m}\right)\end{array}$ & $\begin{array}{c}A_{\mathrm{v}} \\
\left(\mathrm{cm}^{2} \mathrm{rad} / \mathrm{m}\right)\end{array}$ & $\begin{array}{c}\Omega_{\mathrm{c}} \\
(\mathrm{rad} / \mathrm{m})\end{array}$ & $\begin{array}{c}\Omega_{\mathrm{s}} \\
(\mathrm{rad} / \mathrm{m})\end{array}$ & Passenger Train & Freight Train \\
\hline 1 & 3.3634 & 1.2107 & 0.8245 & 0.6046 & 24 & 16 \\
\hline 2 & 1.2107 & 1.0181 & 0.8245 & 0.9308 & 48 & 40 \\
\hline 3 & 0.4128 & 0.6816 & 0.8245 & 0.8520 & 96 & 64 \\
\hline 4 & 0.3027 & 0.5376 & 0.8245 & 1.1312 & 128 & 96 \\
\hline 5 & 0.0762 & 0.2095 & 0.8245 & 0.8209 & 144 & 128 \\
\hline 6 & 0.0339 & 0.0339 & 0.8245 & 0.4380 & 176 & 176 \\
\hline
\end{tabular}

Herein, the test train, composed of two locomotives, six loaded wagons, and 14 empty wagons with the static axle weights $=23 \mathrm{t}, 20.6 \mathrm{t}$, and $5.6 \mathrm{t}$, respectively, travelled over the Baihe Bridge at a designated speed of $80 \mathrm{~km} / \mathrm{h}$. The main parameters of both the locomotive and wagon, such as geometric dimension, mass, moment of inertia, spring stiffness and damping, are reported in Table 3. In order to calculate the two parameters in the Rayleigh damping formulation, an identical modal damping ratio is considered as $1 \%$ for the fundamental modes of the Baihe Bridge involved in the calculation $[6,33]$. The time step selected to solve the equation of motion of the TTB system (i.e., Equation (1)) is $0.005 \mathrm{~s}$. A time step of $0.01 \mathrm{~s}$ has been used to perform train-bridge dynamic analysis focusing on acceleration and displacement response of the bridge structure [29]. Since the high-frequency contents of the stress data are usually fewer than that of the accelerations, $0.005 \mathrm{~s}$ is considered sufficient to capture the high-frequency stresses considering the loading frequency (e.g., train speed), low natural frequencies of the structure, and frequency characteristics of the stress response.

Table 3. Main parameters of the test train.

\begin{tabular}{|c|c|c|c|}
\hline Parameter & Unit & Locomotive & Wagon \\
\hline Mass of the car-body & $\mathrm{kg}$ & $9.05 \mathrm{e} 4$ & $1.56 \mathrm{e} 4$ \\
\hline Moment of inertia of car-body around longitudinal axis & $\mathrm{kg} \mathrm{m}^{2}$ & $8.88 \mathrm{e} 4$ & $2.66 \mathrm{e} 4$ \\
\hline Moment of inertia of car-body around lateral axis & $\mathrm{kg} \mathrm{m}^{2}$ & $2.88 \mathrm{e} 6$ & $2.66 \mathrm{e} 5$ \\
\hline Moment of inertia of car-body around vertical axis & $\mathrm{kg} \mathrm{m}^{2}$ & $2.88 \mathrm{e} 6$ & $2.84 \mathrm{e} 5$ \\
\hline Mass of the bogie & $\mathrm{kg}$ & $1.02 \mathrm{e} 4$ & $1.13 \mathrm{e} 3$ \\
\hline Moment of inertia of bogie around longitudinal axis & $\mathrm{kg} \mathrm{m} \mathrm{m}^{2}$ & $5 \mathrm{e} 3$ & $1.92 \mathrm{e} 2$ \\
\hline Moment of inertia of bogie around lateral axis & $\mathrm{kg} \mathrm{m}^{2}$ & $2.26 \mathrm{e} 4$ & $4.19 \mathrm{e} 2$ \\
\hline Moment of inertia of bogie around vertical axis & $\mathrm{kg} \mathrm{m} \mathrm{m}^{2}$ & $2.26 \mathrm{e} 4$ & $4.19 \mathrm{e} 2$ \\
\hline Mass of the wheelset & $\mathrm{kg}$ & $4.52 \mathrm{e} 3$ & $1.2 \mathrm{e} 3$ \\
\hline Moment of inertia of wheelset around longitudinal axis & $\mathrm{kg} \mathrm{m}^{2}$ & $3.26 \mathrm{e} 4$ & $7.4 \mathrm{e} 2$ \\
\hline Moment of inertia of wheelset around vertical axis & $\mathrm{kg} \mathrm{m}^{2}$ & $3.26 \mathrm{e} 4$ & $7.4 \mathrm{e} 2$ \\
\hline Primary vertical spring stiffness & $\mathrm{N} / \mathrm{m}$ & $1.47 \mathrm{e} 6$ & $1.7 \mathrm{e} 7$ \\
\hline Primary lateral spring stiffness & $\mathrm{N} / \mathrm{m}$ & $2.65 \mathrm{e} 6$ & $3.6 \mathrm{e} 6$ \\
\hline Primary longitudinal spring stiffness & $\mathrm{N} / \mathrm{m}$ & 0 & $3.6 \mathrm{e} 6$ \\
\hline Secondary vertical spring stiffness & $\mathrm{N} / \mathrm{m}$ & $6.62 \mathrm{e} 6$ & $5.32 \mathrm{e} 6$ \\
\hline Secondary lateral spring stiffness & $\mathrm{N} / \mathrm{m}$ & $5.5 \mathrm{e} 7$ & $4.14 \mathrm{e} 6$ \\
\hline Secondary longitudinal spring stiffness & $\mathrm{N} / \mathrm{m}$ & 0 & $6.5 \mathrm{e} 6$ \\
\hline Primary vertical damping & $\mathrm{N} \mathrm{s} / \mathrm{m}$ & $1.2 \mathrm{e} 5$ & $3 e 3$ \\
\hline Primary lateral damping & $\mathrm{N} \mathrm{s} / \mathrm{m}$ & 0 & 0 \\
\hline Primary longitudinal damping & $\mathrm{N} \mathrm{s} / \mathrm{m}$ & 0 & 0 \\
\hline Secondary vertical damping & $\mathrm{N} \mathrm{s} / \mathrm{m}$ & $7.2 \mathrm{e} 4$ & $3 e 3$ \\
\hline Secondary lateral damping & $\mathrm{N} \mathrm{s} / \mathrm{m}$ & $1 \mathrm{e} 5$ & 0 \\
\hline Secondary longitudinal damping & $\mathrm{N} \mathrm{s} / \mathrm{m}$ & 0 & 0 \\
\hline Half span of the primary suspension system & $\mathrm{m}$ & 1.025 & 1 \\
\hline Half span of the secondary suspension system & $\mathrm{m}$ & 1.025 & 1 \\
\hline Half distance between two wheelsets & $\mathrm{m}$ & 1.8 & 0.875 \\
\hline Half distance between two bogies & $\mathrm{m}$ & 6.0 & 4.35 \\
\hline Half distance between two car-body couplers & $\mathrm{m}$ & 21.1 & 13.438 \\
\hline Wheel radius & $\mathrm{m}$ & 0.525 & 0.42 \\
\hline Distance between the car-body and the secondary suspension system & $\mathrm{m}$ & 1.744 & 0.74 \\
\hline Distance between the secondary suspension system and bogie & $\mathrm{m}$ & 0.010 & 0.59 \\
\hline Distance between the bogie and wheelsets & $\mathrm{m}$ & 0.55 & 0.015 \\
\hline
\end{tabular}


Figure 6 shows the computed and measured stress time-histories associated with the instrumented cross-sections of the lower chord, post, stringer, and floor beam (Figure 2). The two sets of stress time-histories are processed with a low-pass filter of $30 \mathrm{~Hz}$, considering modal analysis results where the natural frequencies of the first 100 bridge modes of vibration are below about $9.06 \mathrm{~Hz}$. Moreover, the sampling frequency adopted in the field test is $128 \mathrm{~Hz}$ for stress data collection. It can be seen from the figure that good agreement is achieved between the two sets of stress data. In addition, stress ranges and their cycle counts generated from stress time-histories of the stringer (Figure $6 c$ ) by using the rain-flow counting method [34] are further compared as shown in Figure 7. The comparison results shown in Figures 6 and 7 suggest that the stresses of critical details obtained from multi-scale dynamic analysis of the TTB system can be used to perform fatigue evaluation.

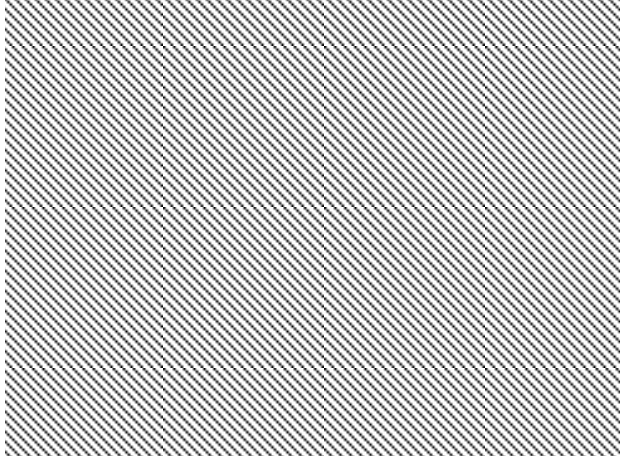

(a)

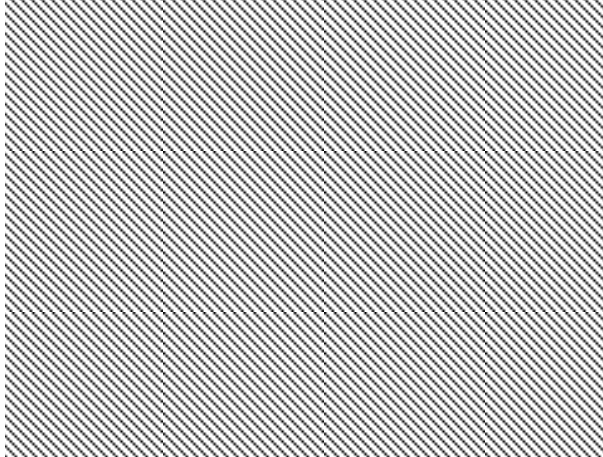

(c)

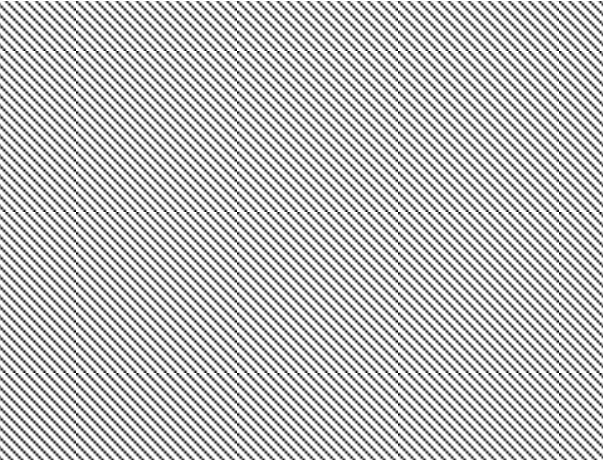

(b)

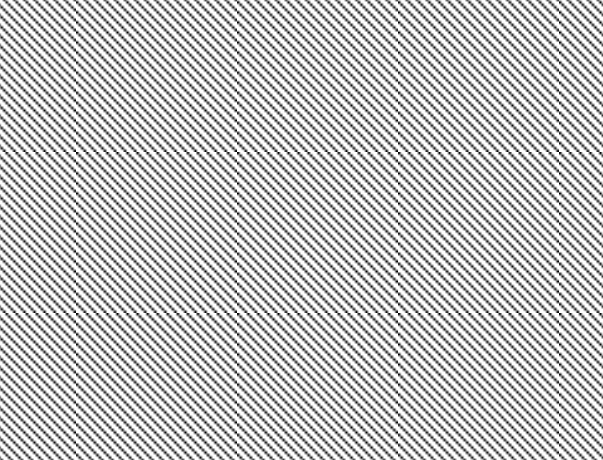

(d)

Figure 6. Stress time-histories of the Baihe Bridge obtained from field test and TTB system analysis: (a) lower chord; (b) post; (c) stringer; and (d) floor beam.

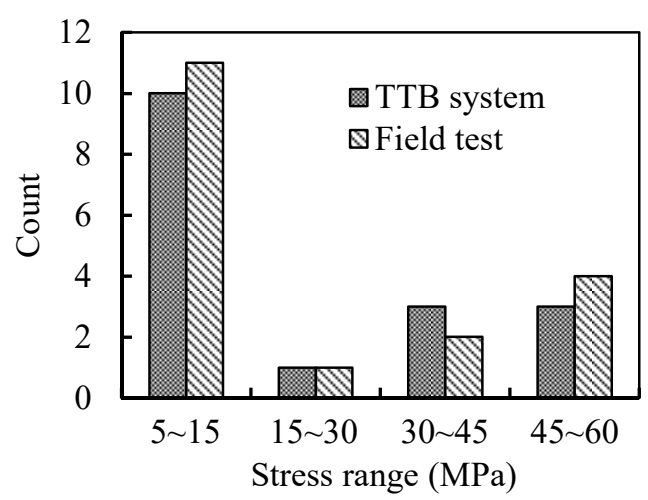

Figure 7. Stress range histograms of the stringer resulting from field test and multi-scale vibration analysis of TTB system. 


\section{Fatigue Load Effects}

Fatigue damage in steel bridges can occur due to the cyclic loads, e.g., train loading. Therefore, it is necessary to acquire train information including daily numbers of passage, marshalling, axle weight, running speed and so on in the service history of the Baihe Bridge. A comprehensive investigation was carried out by Zhang et al. [35] on 54 main railway lines in China including the Beijing-Tongliao line where the Baihe Bridge is located. In their study, the operating trains in the Beijing-Tongliao line were categorized into two types, i.e., passenger train and freight train. The passenger train consists of one locomotive and 20 cars with the axle weights $=23 \mathrm{t}$ and $15.4 \mathrm{t}$, respectively. The freight train is comprised of one locomotive, 25 open-top cars, 11 covered cars, four tank cars, and three flat cars with the net axle weights $=23 t, 5.5 t, 6.0 t, 5.5 t$, and $5.5 t$, respectively. It should be noted that each type of freight car features several values of the actual axle weights depending on the amount of carried goods. Numbers of the passenger and freight train passage per day are 22 and 28 respectively. More information on the passenger and freight trains can be found in Zhang et al. [35].

During the field test in 2011, running speeds of the freight trains were measured. The average speed was found to be $60 \mathrm{~km} / \mathrm{h}$ [16]. In addition, train speeds were increased in China's railway network after 1997 since a campaign aiming at speed-up of the national railway system was launched by the former Ministry of Railway. Consequently, it is assumed in this study that the freight trains ran at the speed of $40 \mathrm{~km} / \mathrm{h}$ before 1997. Generally, passenger trains have higher speeds compared with the freight ones. Therefore, the speeds of passenger trains before and after 1997 are considered as $50 \mathrm{~km} / \mathrm{h}$ and $70 \mathrm{~km} / \mathrm{h}$, respectively.

Stress responses of the stringer-to-floor-beam bracket due to the abovementioned passenger and freight trains are computed through the multi-scale vibration analysis of the TTB system as discussed earlier.

Figures 8 and 9 show the distribution of stresses on the stringer-to-floor-beam bracket analyzed (Figure 2) at two typical time instants induced by the passenger and freight trains of the two loading periods (i.e., 1980-1997 and after 1997). It can be seen in the figures that the stress amplitudes obtained from the operating trains differ significantly. However, in all scenarios the stress distributions in the bracket are similar. The highest stresses appear in the areas (red regions in Figures 8 and 9) around the end of welds connecting the vertical plate and the bottom flange of the stringer. This intense stress response in the high-stress areas is partly attributed to the stress concentration effects resulting from the geometric irregularity and discontinuity around the cope hole. The maximum stress is caused by the freight train with the speed $=60 \mathrm{~km} / \mathrm{h}$, reaching $348 \mathrm{MPa}$. Nevertheless, it is smaller compared with the material yield strength $430 \mathrm{MPa}$. Moreover, the stress variations associated with the high-stress area are also more significant than that observed in other areas of the stringer-to-floor-beam bracket.

In addition, time-histories of the dynamic stresses associated with the high-stress area of the bracket are displayed in Figure 10. It is found in this figure that both the stress amplitudes and variations produced by the freight train are significantly larger compared with those by the passenger train. Therefore, the freight train will contribute the majority to the fatigue damage. No considerable differences in the amplitudes and variations of stress time-histories due to the passenger trains of $50 \mathrm{~km} / \mathrm{h}$ and $70 \mathrm{~km} / \mathrm{h}$ can be observed. Yet dynamic stress variations corresponding to the freight train with the speed $=60 \mathrm{~km} / \mathrm{h}$ are more significant in comparison with that related to the freight train with the speed $=40 \mathrm{~km} / \mathrm{h}$. As a result, it is anticipated that fatigue damage in the analyzed bracket accumulated in loading period 2 (after 1997) would be larger than that in loading period 1 (1980-1997). It should be noted that the influence of strain rate on the fatigue crack propagation rate will be ignored in the following fatigue analysis. Considering the low train speeds and modal frequencies of the Baihe Bridge, the strain rate is within the regular range for the Baihe Bridge and its influence can be negligible. 


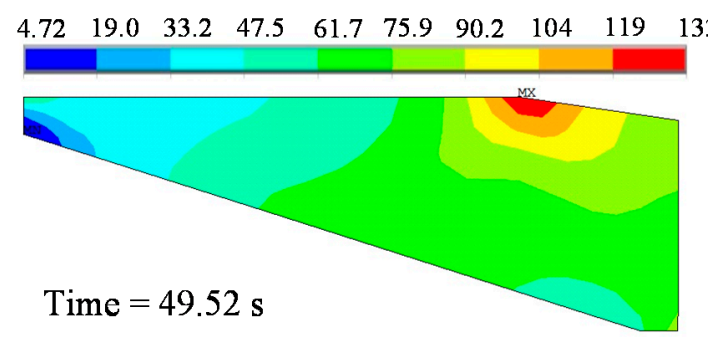

(a)

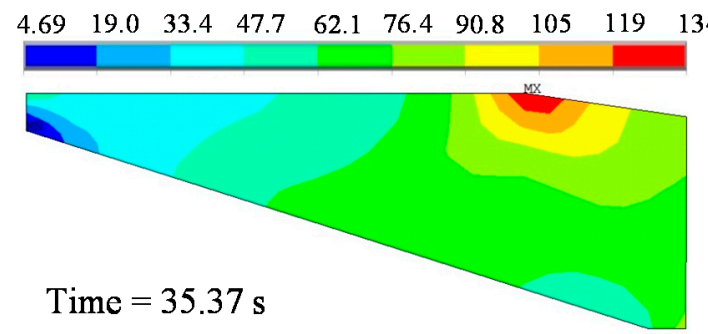

(c)

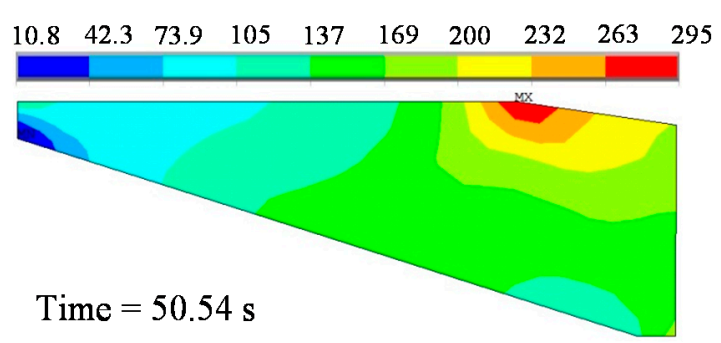

(b)

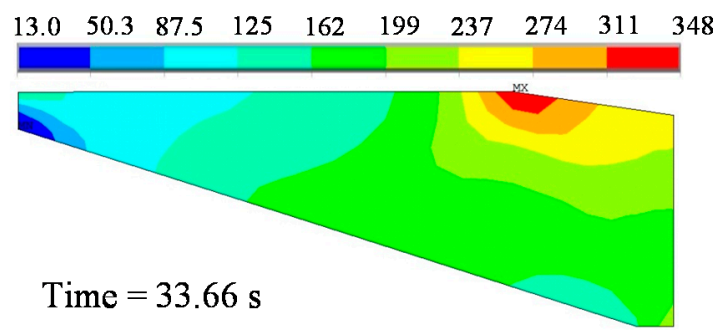

(d)

Figure 8. Peak stress distribution in the stringer-to-floor-beam bracket produced by: (a) passenger train, $50 \mathrm{~km} / \mathrm{h}$; (b) freight train, $40 \mathrm{~km} / \mathrm{h}$; (c) passenger train, $70 \mathrm{~km} / \mathrm{h}$; and (d) freight train, $60 \mathrm{~km} / \mathrm{h}$ (unit: $\mathrm{MPa}$ ).

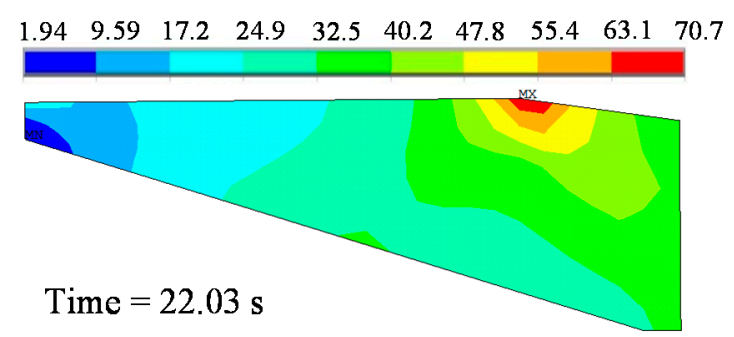

(a)

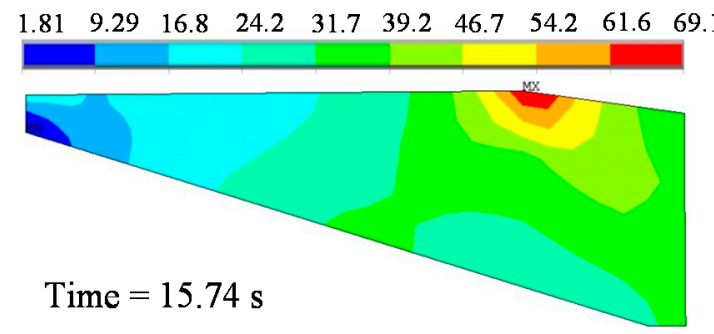

(c)

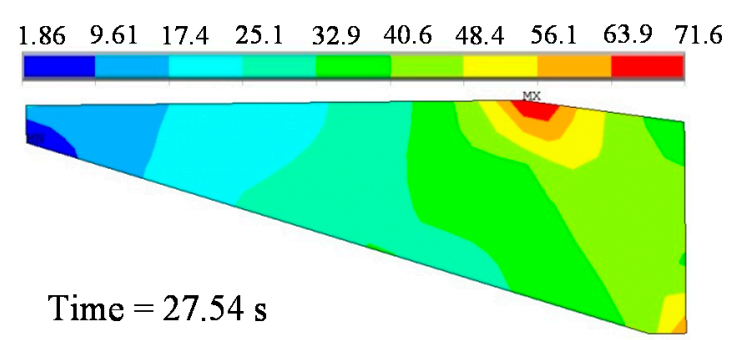

(b)

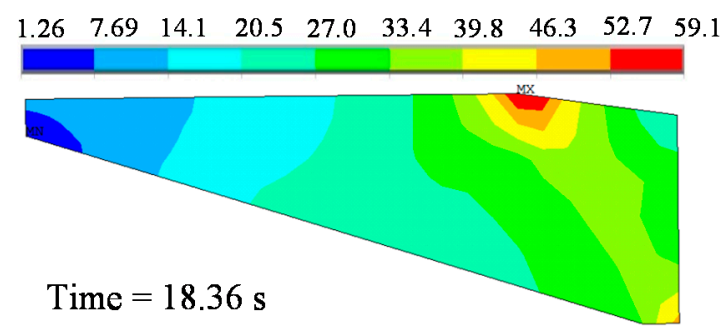

(d)

Figure 9. The stress distribution when the locomotive of: (a) passenger train, $50 \mathrm{~km} / \mathrm{h}$; (b) freight train, $40 \mathrm{~km} / \mathrm{h}$; (c) passenger train, $70 \mathrm{~km} / \mathrm{h}$; and (d) freight train, $60 \mathrm{~km} / \mathrm{h}$ arrives at the position above the critical stringer-to-floor-beam bracket (unit: $\mathrm{MPa}$ ). 


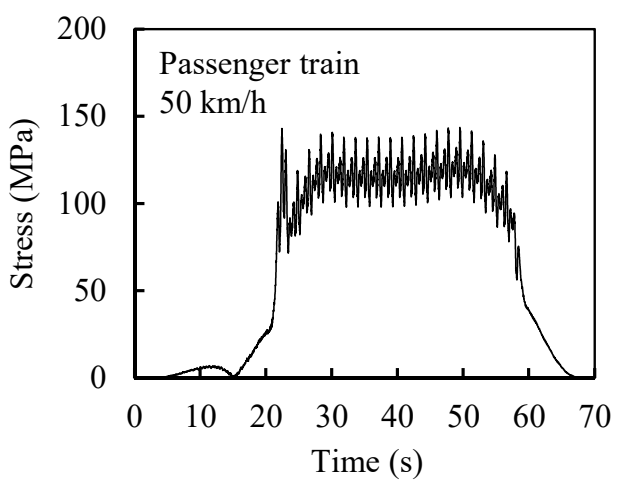

(a)

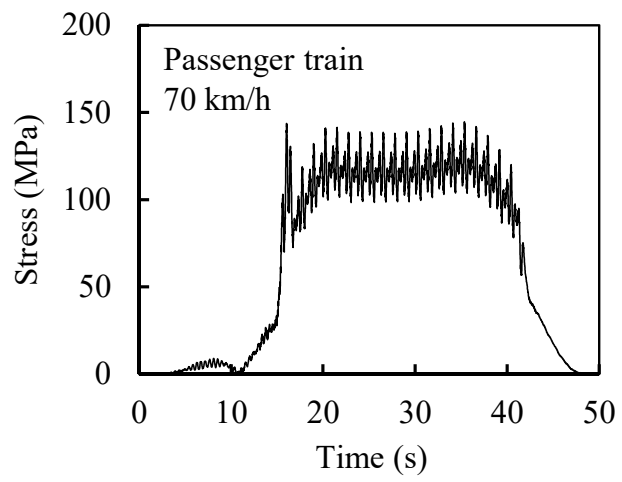

(c)

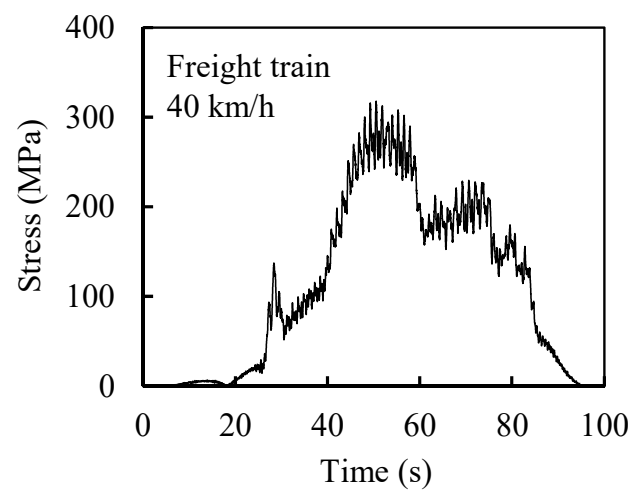

(b)

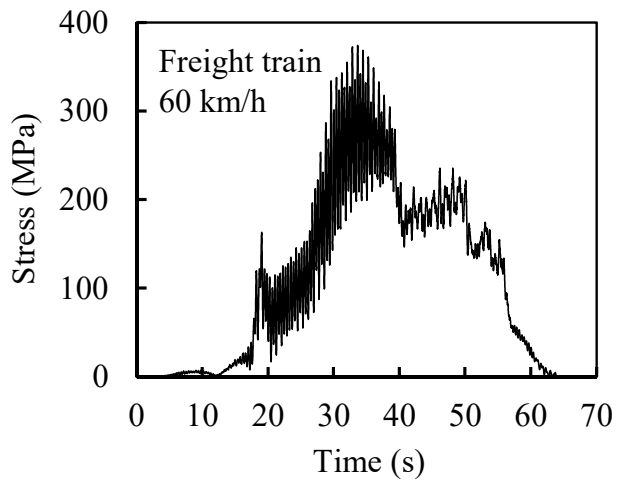

(d)

Figure 10. Time-histories of the stresses in the high-stress area of the stringer-to-floor-beam bracket: (a) passenger train, $50 \mathrm{~km} / \mathrm{h}$; (b) freight train, $40 \mathrm{~km} / \mathrm{h}$; (c) passenger train, $70 \mathrm{~km} / \mathrm{h}$; and (d) freight train, $60 \mathrm{~km} / \mathrm{h}$.

\section{Fatigue Crack Propagation Analysis}

In this section, fatigue crack propagation analysis of the analyzed bracket is performed based on the computed fatigue load effects and LEFM theory. The influence of track irregularity and operating speed on the crack propagation life of the detail is discussed.

\subsection{Fatigue Life of the Bracket}

As discussed in the previous section, fatigue cracks are likely to initiate and propagate in the high-stress area of the stringer-to-floor-beam bracket. Since stress responses of the bracket are within the elastic range, based on the LEFM theory, Paris law characterizing the crack propagation relationship is adopted as [36]

$$
\frac{\mathrm{d} a}{\mathrm{~d} N}=C(\Delta K)^{m}
$$

where $a$ is the crack length; $N$ is the number of stress cycles; $C$ and $m$ are the material constants; and $\Delta K$ is the stress intensity factor range. Equation (5) defines the relationship between the crack growth rate $\mathrm{d} a / \mathrm{d} N$ and the stress intensity factor $K$, which can be expressed as:

$$
K=Y \cdot \sigma \cdot \sqrt{\pi a}
$$

where $Y$ is the dimensionless factor, which is associated with the crack geometry and applied loads; and $\sigma$ is the applied stress. Accordingly, the stress intensity factor range $\Delta K$ can be written as:

$$
\Delta K=\gamma \cdot \Delta \sigma \cdot \sqrt{\pi a}
$$


where $\Delta \sigma$ is the constant-amplitude stress range. Combining Equations (5) and (7), fatigue life in terms of stress cycle count $N$ associated with the stress range $\Delta \sigma$ can be obtained as:

$$
N=\int_{a_{0}}^{a_{\mathrm{c}}} \frac{\mathrm{d} a}{C(\Delta K)^{m}}=\int_{a_{0}}^{a_{\mathrm{c}}} \frac{\mathrm{d} a}{C(Y \Delta \sigma \sqrt{\pi a})^{m}}
$$

where $a_{0}$ and $a_{\mathrm{c}}$ are the initial and critical crack length, respectively. If the dimensionless factor $Y$ is a constant, through the integration operation of Equation (8), an explicit expression of fatigue life $N$ can be obtained as:

$$
N=\frac{2}{(2-m) \cdot C \cdot(Y \Delta \sigma \sqrt{\pi})^{m}}\left(a_{\mathrm{c}}^{\frac{2-m}{2}}-a_{0}^{\frac{2-m}{2}}\right), m \neq 2
$$

It should be noted that Equations (8) and (9) only provide fatigue life estimation related to the crack propagation. Since micro-cracks generally exist when the bridge is completed and put into service, fatigue life associated with the crack initiation may be conservatively ignored. In addition, the calculation of fatigue life $N$ and stress intensity factor $K$ requires knowledge of the dimensionless factor $Y$. As discussed earlier, fatigue cracks tend to initiate from the upper border of the vertical plate of the stringer-to-floor-beam bracket (Figure 3). Therefore, an empirical formula of $Y$ for single edge crack is adopted in this study as [37]

$$
Y=\sqrt{\frac{2 b}{\pi a} \tan \frac{\pi a}{2 b}} \cdot \frac{0.752+2.02\left(\frac{a}{b}\right)+0.37\left(1-\sin \frac{\pi a}{2 b}\right)^{3}}{\cos \left(\frac{\pi a}{2 b}\right)}
$$

where $b$ is the plate width. Equation (10) indicates that $Y$ is the function of the crack length and plate dimension. As a result, the closed-form expression of fatigue life $N$, i.e., Equation (9), may become unavailable due to the difficulty in the integration of Equation (8). In the present analysis, a numerical integration procedure is developed to obtain the fatigue crack propagation life.

As shown in Figure 10, the Baihe Bridge always sustains variable-amplitude stresses subjected to the moving passenger and freight trains. For the sake of the application of Equation (8), the variable-amplitude stress ranges associated with the critical stringer-to-floor-beam bracket are converted into a constant-amplitude stress range, i.e., the equivalent stress range $\Delta S_{\text {eq }}$ expressed as [38]

$$
\Delta S_{\mathrm{eq}}=\left[\sum \frac{n_{i}}{\sum n_{i}} \cdot\left(\Delta \sigma_{i}\right)^{3}\right]^{1 / 3}
$$

where $n_{i}$ is the number of applied stress cycles corresponding to the stress range $\Delta \sigma_{i} ; \sum n_{i}$ is the total number of stress cycles in a stress block. Herein, one stress block is defined as the stress time-histories generated by 22 passenger train passages and 28 freight train passages in an entire day. Equation (11) indicates that the fatigue damage caused by the constant-amplitude equivalent stress range $\Delta S_{\text {eq }}$ is equal to that produced by the variable-amplitude stress ranges $\Delta \sigma_{i}$. Consequently, the number of stress cycles $N$ required for the crack propagation from initial length $a_{0}$ to critical length $a_{\mathrm{c}}$ can be rewritten as:

$$
N=\int_{a_{0}}^{a_{\mathrm{c}}} \frac{\mathrm{d} a}{C\left(Y \Delta S_{\mathrm{eq}} \sqrt{\pi a}\right)^{m}}
$$

In this study, fatigue stresses in the high-stress area of the stringer-to-floor-beam bracket obtained from the multi-scale vibration analysis of the coupled TTB system associated with both the passenger and freight trains are processed to generate the stress range histograms using the rain-flow counting method. Specifically, element stress results extracted from the bridge FE model corresponding to the high-stress area of the bracket are considered herein. Subsequently, the equivalent stress range $\Delta S_{\text {eq }}$ is calculated based on the stress range histogram of one stress block. Fatigue life $N$ is then estimated 
by assuming a small crack length increment at each step of iteration and numerically solving the integration shown in Equation (12).

Values of the initial crack length can impact the estimation results of fatigue life [39]. These values can be determined by performing an in-situ nondestructive test on the components of the considered bridge with initial flaws. Due to the lack of initial crack size data associated with the investigated bracket, in this study several initial crack length values in the range of $0.1 \mathrm{~mm}$ to $0.25 \mathrm{~mm}$ recommended by BS 7608 [40] are adopted considering the uncertainty in determination of the initial length. The critical crack length represents a certain crack size beyond which fracture failures or loss of load-carrying capacity will occur to the structural details. Accordingly, this value could be determined by fracture mechanics or assuming a size proportional to the dimensions of structural components, e.g., plate width or thickness. In addition, accurate identification of the two material constants for applying the Paris law in Equation (5), i.e., $C$ and $m$, usually requires a fatigue crack growth rate test. These two constants take the values of $1.26 \times 10^{-13}$ and 3.0 respectively, based on the investigation in Fisher 1984 [41].

Figure 11 shows the computed crack propagation history of the stringer-to-floor beam bracket from the year 1980 when the Baihe Bridge was opened to railway traffic. Four different initial crack sizes $a_{0}=0.1 \mathrm{~mm}, 0.15 \mathrm{~mm}, 0.2 \mathrm{~mm}$, and $0.25 \mathrm{~mm}$ are considered. Additionally, the critical crack length $a_{\mathrm{c}}=85 \mathrm{~mm}$ is adopted herein, which represents half of the bracket width. It can be observed in Figure 11 that the crack propagation amount in the loading period 1980-1997 is quite small; however, after 1997, the crack grows quickly because the running speeds of the passenger train and freight train respectively increase to $70 \mathrm{~km} / \mathrm{h}$ and $60 \mathrm{~km} / \mathrm{h}$ as discussed earlier. Therefore, train speeds can significantly affect the fatigue cracking of the bracket, and this effect will be further discussed later on. When the initial crack size $a_{0}$ takes the values of $0.1 \mathrm{~mm}, 0.15 \mathrm{~mm}, 0.2 \mathrm{~mm}$, and $0.25 \mathrm{~mm}$, fatigue life in terms of year needed for the crack length to reach $85 \mathrm{~mm}$ is calculated as $24.9,23.5,22.6$, and 21.9 years respectively.

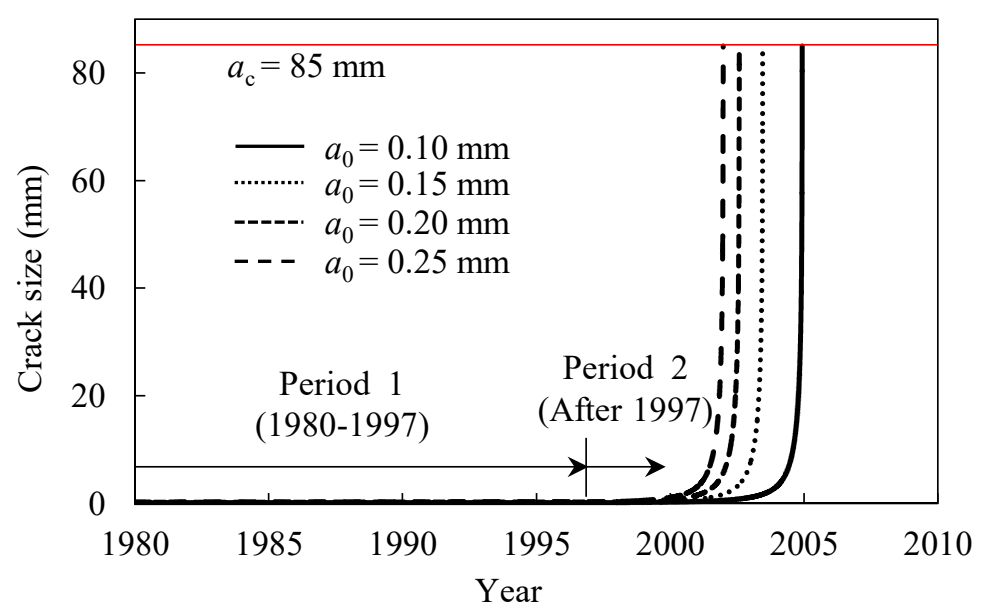

Figure 11. Fatigue crack propagation curves of the stringer-to-floor-beam bracket.

It was reported in Hou et al. [19] that a $60 \mathrm{~mm}$ crack was detected in the bracket under consideration in 2006 and a round hole was drilled to prevent further development of the crack (Figure 12). Based on the results shown in Figure 11, the year associated with a critical crack size of $60 \mathrm{~mm}$ and initial crack size of $0.1 \mathrm{~mm}$ is about 2004. Hence, the predicted crack growth rate is slightly greater than the situation in the real world. It should be noted in Figure 11 that the crack propagates from $60 \mathrm{~mm}$ to $85 \mathrm{~mm}$ within one year (2004), since the crack size increases very quickly as shown in Figure 11 after it exceeds a certain value, e.g., $10 \mathrm{~mm}$ in the present analysis. Figure 13 shows the relationship between the crack growth rate, $\mathrm{d} a / \mathrm{d} N$, and the relative crack size, $a / a_{\mathrm{c}}$, with the initial crack length $a_{0}=0.1 \mathrm{~mm}$. As shown in this figure, the crack size increment per stress cycle climbs with the increase in the crack size. This can provide explanations for the sharp parts of the curves in Figure 11. It can be concluded that the fatigue crack propagation life is less sensitive to the critical size $a_{\mathrm{c}}$ in comparison with the initial size $a_{0}$. 


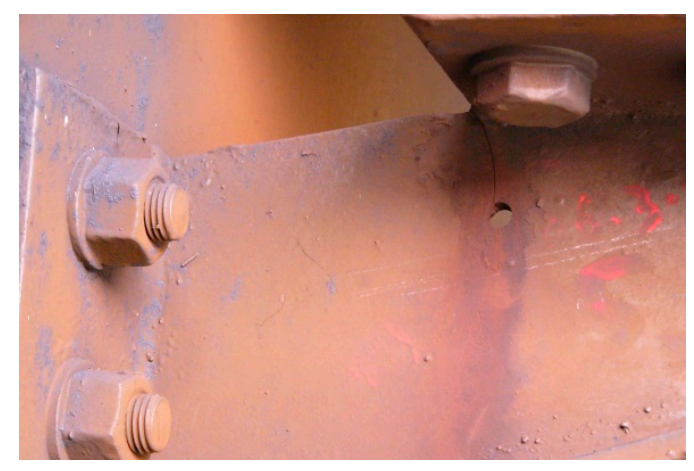

Figure 12. The photo of the cracked bracket.

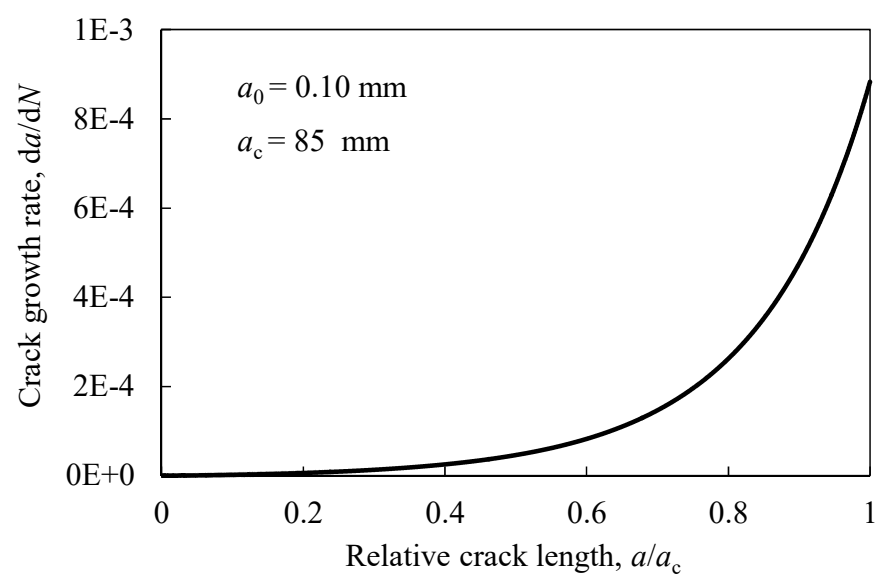

Figure 13. Crack growth rate $\mathrm{d} a / \mathrm{d} N$ versus relative crack length $a / a_{\mathrm{c}}$.

\subsection{Effects of Track Irregularity and Train Speed}

Track irregularities are regarded as the most important excitation of the TTB system [24]. Five different classes of track irregularity, i.e., class 2 to class 6 are considered to investigate their influence on the fatigue crack propagation life. Using Equation (4) and the parameters reported in Table 2, four additional sets of track irregularity samples corresponding to class 2, 3, 4, and 6 were generated to perform multi-scale coupled analysis of the TTB system. Figure 14 shows the fatigue crack propagation curves resulting from the five different classes of track irregularity under $a_{0}=$ $0.1 \mathrm{~mm}$. Generally, the crack propagation life rises with the decrease in severity of track irregularities. If the track irregularity class is improved by one grade to class 6 for the Baihe Bridge, the fatigue life of the bracket analyzed will be extended to the year 2082 as shown in Table 4 . It is also found in the table that the number of stress cycles $\sum n_{i}$ in a stress block increases with the increase in degree of track irregularities, whereas a similar tendency is not present for the equivalent stress range $\Delta S_{\text {eq }}$. For purposes of illustration, maximum vertical, lateral, and torsional wheel-rail forces obtained from the five different classes of track and perfect track (without considering irregularities) are reported in Table 5, corresponding to the first wheelset in the locomotive of the freight train running at $60 \mathrm{~km} / \mathrm{h}$. A significant increase can be observed in the wheel-rail interactions in all directions with the deterioration of track condition. These observations suggest that track conditions have considerable effects on the fatigue life of structural details in the bridge deck system. Since dynamic responses of the TTB system to the excitation of track irregularities can change with vehicle and bridge parameters, accurate quantification of the abovementioned effects calls for specific analysis of the TTB system. 


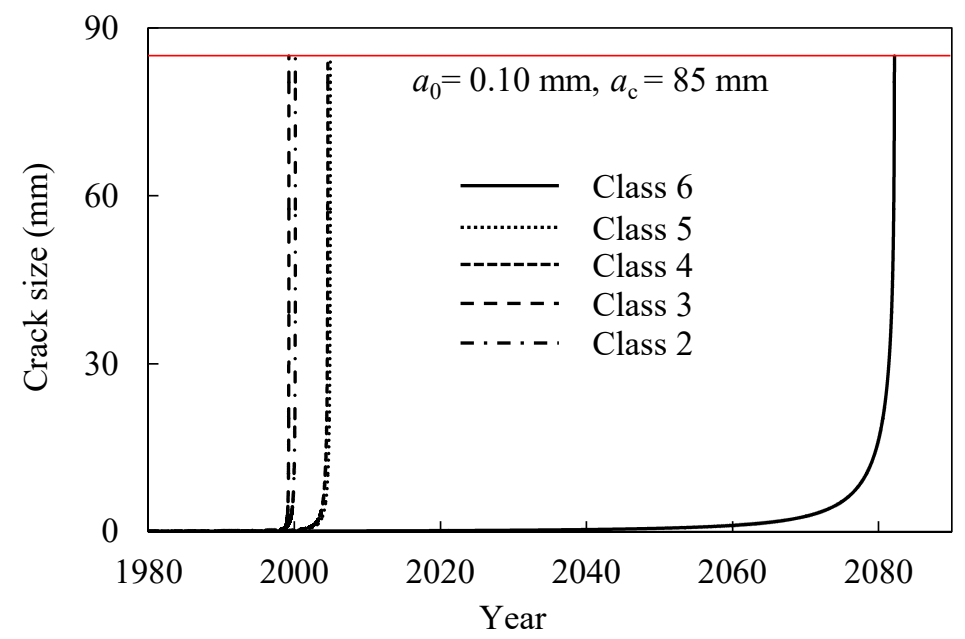

Figure 14. Fatigue crack propagation curves obtained from different classes of track irregularity.

Table 4. Fatigue evaluation results under various track irregularity classes.

\begin{tabular}{|c|c|c|c|c|c|}
\hline \multirow{2}{*}{$\begin{array}{c}\text { Track Irregularity } \\
\text { Class }\end{array}$} & \multicolumn{2}{|c|}{$\Delta S_{\mathrm{eq}}(\mathrm{MPa})$ in Equation (12) } & \multicolumn{2}{|c|}{$\sum n_{i}$ in Equation (12) } & \multirow{2}{*}{$\begin{array}{c}\text { Time of the Crack Size } \\
\text { Reaching } 85 \mathrm{~mm} \\
a_{0}=0.1 \mathrm{~mm}, a_{\mathrm{c}}=85 \mathrm{~mm}\end{array}$} \\
\hline & 1980-1997 & After 1997 & 1980-1997 & After 1997 & \\
\hline 2 & 18.55 & 44.87 & 69810 & 43128 & 2000 \\
\hline 3 & 11.25 & 70.28 & 61440 & 34140 & 1999 \\
\hline 4 & 13.75 & 39.19 & 57702 & 34574 & 2004 \\
\hline 5 & 11.45 & 41.40 & 48804 & 30584 & 2004 \\
\hline 6 & 9.09 & 18.97 & 43770 & 27486 & 2082 \\
\hline
\end{tabular}

Table 5. Maximum wheel-rail forces associated with the first wheelset in the locomotive of the freight train $(60 \mathrm{~km} / \mathrm{h})$ with and without track irregularities considered.

\begin{tabular}{cccc}
\hline Track Irregularities & $\begin{array}{c}\text { Vertical Wheel-Rail } \\
\text { Force }(\mathbf{k N})\end{array}$ & $\begin{array}{c}\text { Lateral Wheel-Rail } \\
\text { Force } \mathbf{( k N )}\end{array}$ & $\begin{array}{c}\text { Torsional Wheel-Rail } \\
\text { Moment (kN m) }\end{array}$ \\
\hline Class 2 & 267.5 & 46.9 & 56.7 \\
Class 3 & 250.1 & 23.3 & 48.1 \\
Class 4 & 243.2 & 23.0 & 38.5 \\
Class 5 & 238.3 & 10.7 & 29.1 \\
Class 6 & 229.1 & 5.88 & 9.98 \\
No irregularities & 226.9 & 2.54 & 5.83 \\
\hline
\end{tabular}

In the present analysis, operating speeds of the passenger train and freight train respectively ranging from 50 to $110 \mathrm{~km} / \mathrm{h}$ and 40 to $100 \mathrm{~km} / \mathrm{h}$ with the step of $10 \mathrm{~km} / \mathrm{h}$ are taken into account. A $10 \mathrm{~km} / \mathrm{h}$ speed gap between the passenger and freight train is still adopted as discussed earlier. Therefore, there are overall seven speed combinations considered as shown in Table 6 . Then, the fatigue stresses are computed with multi-scale dynamic analysis of the coupled TTB system subjected to the excitation of class 5 track irregularities.

Crack propagation curves corresponding to the different operating speeds were obtained as shown in Figure 15. Great differences in fatigue life in terms of year can be observed. When the passenger and freight train speeds are respectively $50 \mathrm{~km} / \mathrm{h}$ and $40 \mathrm{~km} / \mathrm{h}$, it takes 224 years for the crack in the stringer-to-floor-beam bracket considered to propagate from $0.1 \mathrm{~mm}$ to $85 \mathrm{~mm}$. Yet the associated time becomes 8 years if the speed combination is $(70,60) \mathrm{km} / \mathrm{h}$. Additionally, The crack propagation curves obtained from speed combinations $(80,70) \mathrm{km} / \mathrm{h}$ and $(110,100) \mathrm{km} / \mathrm{h}$ almost overlap completely, since the equivalent stress range of the $(80,70) \mathrm{km} / \mathrm{h}$ combination is smaller while the stress cycle number in a stress block is larger compared with their counterparts of the $(110,100) \mathrm{km} / \mathrm{h}$ combination as reported in Table 6 . One can observe in the table that train speeds can significantly affect the fatigue load effects (i.e., $\Delta S_{\text {eq }}$ and 
$\sum n_{i}$ ) and further impact the fatigue crack propagation life. Usually, the relationship between the stresses of the bridge and train speeds is not monotonic [15]. Accurate quantification of these effects would require specific analysis since they are associated with multiple factors including dynamic properties of both the train and bridge in the TTB system. Finally, regardless of train speeds, crack propagation within small sizes (e.g., $10 \mathrm{~mm}$ ) forms the majority of the fatigue life as shown in Figure 15 and Table 6. This indicates that maintenance actions could be taken during the early stage of crack propagation.

Table 6. Fatigue evaluation results under various train speeds.

\begin{tabular}{|c|c|c|c|c|c|c|}
\hline \multicolumn{2}{|c|}{ Operating Speed $(\mathrm{km} / \mathrm{h})$} & \multirow{2}{*}{$\begin{array}{l}\Delta S_{\text {eq }}(\mathrm{MPa}) \text { in } \\
\text { Equation (12) }\end{array}$} & \multirow{2}{*}{$\underset{\text { Equation (12) }}{\sum n_{i} \text { in }}$} & \multicolumn{3}{|c|}{ Fatigue Life $N$ in Terms of Stress Cycle Number } \\
\hline $\begin{array}{l}\text { Passenger } \\
\text { Train }\end{array}$ & $\begin{array}{c}\text { Freight } \\
\text { Train }\end{array}$ & & & $\begin{aligned} a_{0} & =0.1 \mathrm{~mm} \\
a_{\mathrm{c}} & =85 \mathrm{~mm}\end{aligned}$ & $\begin{aligned} \mathrm{a}_{0} & =0.1 \mathrm{~mm} \\
a_{\mathrm{c}} & =60 \mathrm{~mm}\end{aligned}$ & $\begin{aligned} a_{0} & =0.1 \mathrm{~mm} \\
a_{\mathrm{c}} & =10 \mathrm{~mm}\end{aligned}$ \\
\hline 50 & 40 & 11.45 & 48804 & $3.9858 \mathrm{e} 9$ & $3.9821 \mathrm{e} 9$ & $3.8042 \mathrm{e} 9$ \\
\hline 60 & 50 & 19.27 & 34602 & $8.3577 \mathrm{e} 8$ & $8.3499 \mathrm{e} 8$ & $7.9769 \mathrm{e} 8$ \\
\hline 70 & 60 & 41.40 & 30584 & $8.4321 \mathrm{e} 7$ & $8.4242 \mathrm{e} 7$ & $8.0479 \mathrm{e} 7$ \\
\hline 80 & 70 & 23.53 & 33160 & $4.5923 \mathrm{e} 8$ & $4.5880 \mathrm{e} 8$ & $4.3830 \mathrm{e} 8$ \\
\hline 90 & 80 & 23.44 & 27460 & $4.6488 \mathrm{e} 8$ & $4.6445 \mathrm{e} 8$ & $4.4370 \mathrm{e} 8$ \\
\hline 100 & 90 & 24.31 & 28418 & $4.1650 \mathrm{e} 8$ & $4.1612 \mathrm{e} 8$ & $3.9753 \mathrm{e} 8$ \\
\hline 110 & 100 & 26.40 & 23382 & $3.2518 \mathrm{e} 8$ & $3.2488 \mathrm{e} 8$ & $3.1036 \mathrm{e} 8$ \\
\hline
\end{tabular}

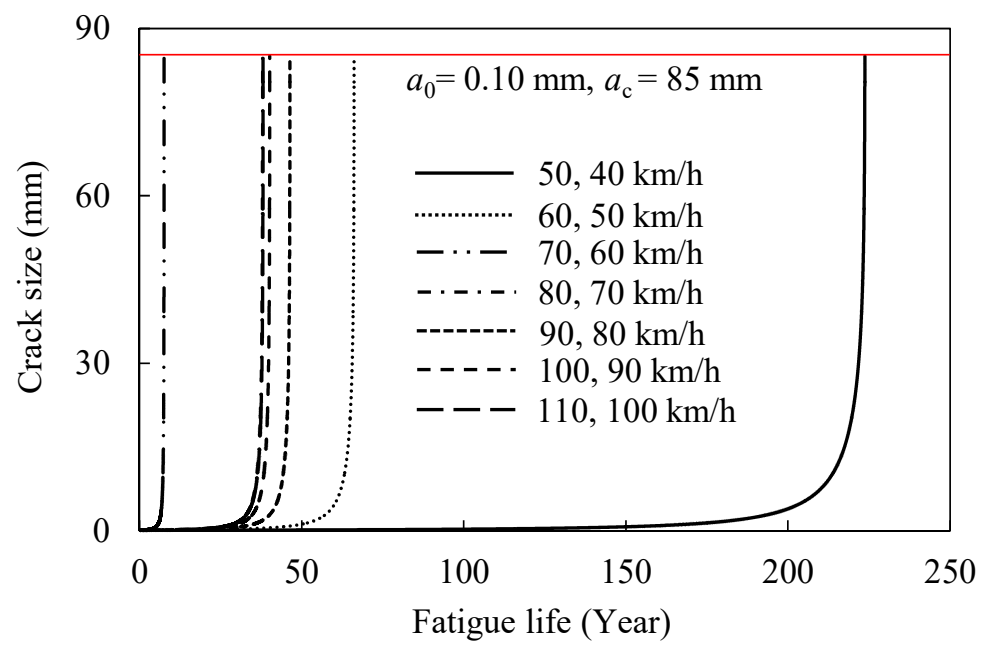

(a)

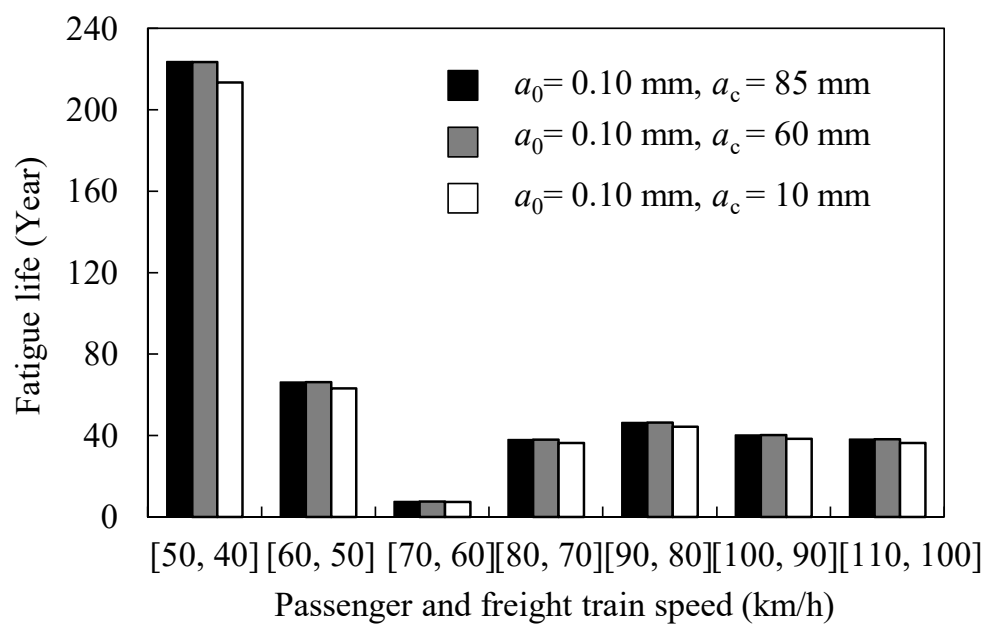

(b)

Figure 15. Effects of operating train speed on fatigue crack propagation life: (a) crack propagation curve; and (b) fatigue life versus train speed. 


\section{Conclusions}

This paper presented a framework for fatigue assessment of structural details in the steel bridges integrating multi-scale coupled dynamic analysis of the TTB system and LEFM theory. The multi-scale FE model of the Baihe Bridge including a refined local shell model located in the area around the fatigue-critical details was established and validated. Based on the multi-scale FE model and the wheel-rail contact relationship, the dynamic equation of the TTB system was formulated to acquire the bridge stresses, which were compared against field measurements. Fatigue stresses obtained from the multi-scale coupled dynamic analysis were used in conjunction with the LEFM to investigate the fatigue crack propagation of the stringer-to-floor-beam bracket. The following conclusions can be drawn:

1. Fatigue stresses of the critical bridge details are successfully calculated through multi-scale dynamic analysis of the TTB system. The incorporation of the multi-scale bridge FE model into the train-bridge interaction model enables accurate and efficient fatigue stress computation of both the bridge primary members and structural details with the coupled dynamic effects of the TTB system also considered.

2. The integration of multi-scale coupled dynamic analysis of the TTB system and LEFM provides an effective tool for enhanced fatigue analysis of the Baihe Bridge, allowing insights into the fatigue crack propagation of structural details in steel bridges.

3. Fatigue life of the critical bracket is extended from the year 2004 to the year 2082 when the track condition of the Baihe Bridge is upgraded to class 6, as prescribed by the U.S. Federal Railroad Administration. The effects of track irregularities on the fatigue crack propagation life of structural details in the bridge deck system can be characterized using the presented framework.

4. Fatigue crack propagation life of the analyzed stringer-to-floor-beam bracket ranges from a few years to more than 100 years depending on the operating train speeds. Train speeds greatly impact the stress range amplitude and stress cycle count associated with the bracket. The effects of the train speed are well captured by multi-scale dynamic analysis of the coupled TTB system.

Author Contributions: Conceptualization, H.L. and G.W.; methodology, H.L.; formal analysis, H.L.; data curation, H.L.; writing — original draft preparation, H.L.; writing—review and editing, G.W.; project administration, G.W.; funding acquisition, G.W. and H.L. All authors have read and agreed to the published version of the manuscript.

Funding: This research was funded by the National Natural Science Foundation of China Grant Nos. 51708112 and 51525801.

Conflicts of Interest: The authors declare no conflict of interest.

\section{References}

1. Deng, L.; Wang, W.; Yu, Y. State-of-the-art review on the causes and mechanisms of bridge collapse. J. Perform. Constr. Facil. 2016, 30, 04015005-1-04015005-13. [CrossRef]

2. Liu, Y.; Li, D.R.; Zhang, Z.H.; Zhang, H.P.; Jiang, N. Fatigue load model using the weigh-in-motion system for highway bridges in China. J. Bridge Eng. 2017, 22, 04017011-1-04017011-8. [CrossRef]

3. Siriwardane, S.; Ohga, M.; Dissanayake, R.; Taniwaki, K. Application of new damage indicator-based sequential law for remaining fatigue life estimation of railway bridges. J. Constr. Steel Res. 2008, 64, $228-237$. [CrossRef]

4. Basso, P.; Casciati, S.; Faravelli, L. Fatigue reliability assessment of a historic railway bridge designed by Gustave Eiffel. Struct. Infrastruct. Eng. 2015, 11, 27-37. [CrossRef]

5. Liu, K.; Zhou, H.; Shi, G.; Wang, Y.Q.; Shi, Y.J.; De Roeck, G. Fatigue assessment of a composite railway bridge for high speed trains. Part II: Conditions for which a dynamic analysis is needed. J. Constr. Steel Res. 2013, 82, 246-254. [CrossRef]

6. Lee, H.H.; Jeon, J.C.; Kyung, K.S. Determination of a reasonable impact factor for fatigue investigation of simple steel plate girder railway bridges. Eng. Struct. 2012, 36, 316-324. [CrossRef]

7. Lippi, F.V.; Orland, M.; Salvatore, W. Assessment of the dynamic and fatigue behavior of the Panaro railway steel bridge. Struct. Infrastruct. Eng. 2013, 9, 834-848. [CrossRef] 
8. Zhou, H.; Liu, K.; Shi, G.; Wang, Y.Q.; Shi, Y.J.; De Roeck, G. Fatigue assessment of a composite railway bridge for high speed trains. Part I: Modeling and fatigue critical details. J. Constr. Steel Res. 2013, 82, 234-245. [CrossRef]

9. Wang, F.Y.; Xu, Y.L.; Sun, B.; Zhu, Q. Dynamic stress analysis for fatigue damage prognosis of long-span bridges. Struct. Infrastruct. Eng. 2019, 15, 582-599. [CrossRef]

10. Garg, V.K.; Chu, K.H.; Wiriyachai, A. Fatigue life of critical members in a railway truss bridge. Earthq. Eng. Struct. Dyn. 1982, 10, 779-795. [CrossRef]

11. Leitão, F.N.; Da Silva, J.G.S.; Da SVellasco, P.C.G.; De Andrade, S.A.L.; De Lima, L.R.O. Composite (steel-concrete) highway bridge fatigue assessment. J. Constr. Steel Res. 2011, 67, 14-24. [CrossRef]

12. Zhang, W.; Cai, C.S. Fatigue reliability assessment for existing bridges considering vehicle speed and road surface conditions. J. Bridge Eng. 2012, 17, 443-453. [CrossRef]

13. Zhang, W.; Cai, C.S.; Pan, F. Fatigue reliability assessment for long-span bridges under combined dynamic loads from winds and vehicles. J. Bridge Eng. 2013, 18, 735-747. [CrossRef]

14. Wang, W.; Deng, L.; Shao, X.D. Fatigue design of steel bridges considering the effect of dynamic vehicle loading and overloaded trucks. J. Bridge Eng. 2016, 21, 04016048-1-04016048-12. [CrossRef]

15. Li, H.L.; Xia, H.; Soliman, M.; Frangopol, D.M. Bridge stress calculation based on the dynamic response of coupled train-bridge system. Eng. Struct. 2015, 99, 334-345. [CrossRef]

16. Li, H.L.; Frangopol, D.M.; Soliman, M.; Xia, H. Fatigue reliability assessment of railway bridges based on probabilistic dynamic analysis of a coupled train-bridge system. J. Struct. Eng. 2016, 142, 04015158-1-04015158-16. [CrossRef]

17. Li, H.L.; Soliman, M.; Frangopol, D.M.; Xia, H. Fatigue damage in railway steel bridges: Approach based on a dynamic train-bridge coupled model. J. Bridge Eng. 2017, 22, 06017006-1-06017006-8. [CrossRef]

18. Zhou, H.; Shi, G.; Wang, Y.Q.; Chen, H.T.; De Roeck, G. Fatigue evaluation of a composite railway bridge based on fracture mechanics through global-local dynamic analysis. J. Constr. Steel Res. 2016, 122, 1-13. [CrossRef]

19. Hou, Y.F.; Yang, Z.M.; Zhang, N. Report on the Routine Inspection of the Baihe Bridge in Jing-Tong Railway Line; Rep. No. 24; Beijing Railway Bureau: Beijing, China, 2012. (In Chinese)

20. ANSYS 15. Computer Software; ANSYS: Canonsburg, PA, USA, 2013.

21. Yang, Y.B.; Yau, J.D.; Wu, Y.S. Vehicle-Bridge Interaction Dynamics: With Applications to High-Speed Railways; World Scientific: Singapore, 2004.

22. Xia, H.; De Roeck, G.; Goicolea, J.M. Bridge Vibration and Controls: New Research; Nova Science: New York, NY, USA, 2012.

23. Zhai, W.M.; Xia, H.; Cai, C.B.; Gao, M.M.; Li, X.Z.; Guo, X.R.; Zhang, N.; Wang, K.Y. High-speed train-track-bridge dynamic interactions-Part I: Theoretical model and numerical simulation. Int. J. Rail Transp. 2013, 1, 3-24. [CrossRef]

24. Zhai, W.M.; Han, Z.L.; Chen, Z.W.; Ling, L.; Zhu, S.Y. Train-track-bridge dynamic interaction: A state-of-the-art review. Veh. Syst. Dyn. 2019, 57, 984-1027. [CrossRef]

25. Yang, S.C.; Hwang, S.H. Train-track-bridge interaction by coupling direct stiffness method and mode superposition method. J. Bridge Eng. 2016, 21, 04016058-1-04016058-16. [CrossRef]

26. Li, H.L.; Xia, H. Fatigue stress analysis of a steel railway bridge using dynamic train-bridge system model. In Proceedings of the Third International Conference on Railway Technology: Research, Development and Maintenance, Cagliari, Italy, 5-8 April 2016; pp. 1-15.

27. Zhai, W.M.; Wang, K.Y.; Cai, C.B. Fundamentals of vehicle-track coupled dynamics. Veh. Syst. Dyn. 2009, 47, 1349-1376. [CrossRef]

28. Guo, W.W.; Xia, H.; De Roeck, G.; Liu, K. Integral model for train-track-bridge interaction on the Sesia viaduct: Dynamic simulation and critical assessment. Comput. Struct. 2012, 112-113, 205-216. [CrossRef]

29. Zhang, N.; Xia, H.; Guo, W.W.; De Roeck, G. A vehicle-bridge linear interaction model and its validation. Int. J. Struct. Stab. Dyn. 2010, 10, 335-361. [CrossRef]

30. MATLAB. Computer Software; MathWorks: Natick, MA, USA, 2015.

31. Garg, V.K.; Dukkipati, R.V. Dynamics of Railway Vehicle System; Academic Press: Toronto, ON, Canada, 1984.

32. Chen, G.; Zhai, W.M.; Zuo, H.F. Comparing track irregularities PSD of Chinese main lines with foreign typical lines by numerical simulation computation. J. China Railw. Soc. 2001, 23, 82-87. (In Chinese)

33. Huang, D.Z. Dynamic analysis of steel curved box girder bridges. J. Bridge Eng. 2001, 6, 506-513. [CrossRef] 
34. Downing, S.D.; Socie, D.F. Simple rainflow counting algorithms. Int. J. Fatigue 1982, 4, 31-40. [CrossRef]

35. Zhang, Y.L.; Xin, X.Z.; Cui, X. Updating fatigue damage coefficient in railway bridge design code in China. J. Bridge Eng. 2012, 17, 788-793. [CrossRef]

36. Paris, P.; Erdogan, F. A critical analysis of crack propagation laws. J. Basic Eng. 1963, 85, 528-534. [CrossRef]

37. Tada, H.; Paris, P.; Irwin, G. The Stress Analysis of Cracks Handbook; Del Research Corporation: Hellertown, PA, USA, 1973.

38. Miner, M.A. Cumulative damage in fatigue. J. Appl. Mech. 1945, 12, A159-A164.

39. Madsen, H.O. Random fatigue crack growth and inspection. In Proceedings of the International Conference on Structural Safety and Reliability ICOSSAR'85, Kobe, Japan, 27-29 May 1985; pp. I-475-I-484.

40. British Standards Institution. Code of Practice for Fatigue Design and Assessment of Steel Structures; BS 7608: London, UK, 1993.

41. Fisher, J.W. Fatigue and Fracture in Steel Bridges: Case Studies; John Willey \& Sons: New York, NY, USA, 1984.

(C) 2020 by the authors. Licensee MDPI, Basel, Switzerland. This article is an open access article distributed under the terms and conditions of the Creative Commons Attribution (CC BY) license (http://creativecommons.org/licenses/by/4.0/). 